\title{
Imaging of Pulmonary Infections
}

\author{
Dinesh Singh
}

\subsection{Introduction}

Pulmonary infections have always been a cause of high morbidity and mortality, particularly in the pediatric and geriatric population and in immunocompromised hosts [1]. Pulmonary infections have various etiologies and have variegated patterns on radiographs and computed tomography (CT). Imaging plays an important role in the initial diagnosis and follow-up of various lung infections. Radiographs can be normal or non-specific during the initial evaluation, and CT findings may be more definitive. CT not only helps with the diagnosis but can also aid in management by guiding the diagnostic and therapeutic procedure. The pulmonary infections spread by direct or indirect contact with the infected host, droplet transmission, or an airborne spread. In rare cases, some infections can also be transmitted by vectors, namely, insect or animal hosts, and rarely by direct invasion from nearby infected organs. Pulmonary infections may have typical imaging patterns and distribution based on the mode of spread. There are a number of well-described imaging patterns of alveolar infections. The localization and morphological features on imaging may help in the diagnosis of infection and identification of mode of infection and, in certain cases, the microorganism responsible for the infection.

\subsection{Patterns of Lung Infections}

\subsubsection{Consolidation}

Consolidation is a typical pattern of a lung infection on a radiograph of the chest, usually initiating as a small focus close to the fissures. Pneumonia can be caused by a variety of organisms like bacteria, bacteria-like organisms like Mycoplasma pneumonia, fungi, or even a number of viruses.

D. Singh $(\bowtie)$

Department of Diagnostic Radiology, Khoo Teck Puat Hospital, Singapore, Singapore
Lobar pneumonia and bronchopneumonia are two distinct patterns of pulmonary infections (Figs. 6.1 and 6.2). Lobar pneumonia results in a homogenous opacity, limited by the fissures and without any associated volume loss. There may be the presence of "air bronchograms" that result from relative sparing of the bronchi, appearing as dark air-filled linear spaces within the exudate-filled alveoli. Lobar pneumonia usually has surrounding ground-glass opacities, better seen on computed tomography (CT), and can have associated complications like an abscess, pleural effusion, or empyema. The opacification of an entire lobe is uncommon nowadays due to early antibiotic treatment, which stops the progress of the infective process. Some cases of lobar pneumonia have typical imaging patterns (Table 6.1) (Fig. 6.3) [2, 3]. However, one should remember that consolidation is not diagnostic of infection and can also be seen in other conditions like pulmonary edema, hemorrhage, organizing pneumonia, vasculitis, and even malignancies.

A unique pattern of lung infection, generally seen in children younger than 12 years of age, is called "round pneumonia" [4]. This pattern of infection is seen in children due to lack of development of interalveolar connections and collateral airways. Typically, occurring as a solitary lesion, these are usually due to bacterial infection, most commonly caused by Streptococcus pneumonia. Round pneumonia can be seen on a chest radiograph as rounded nodular opacity with illdefined margins, commonly involving the superior segments of the lower lobes. Associated air bronchograms are usually confirmatory, thereby preventing delay in diagnosis.

Bronchopneumonia usually results from inhalation and rarely from hematogenous spread of microorganisms and is initially limited in and around the airways. The early airways and peribronchial ground-glass densities spread and become confluent resulting in consolidation (Fig. 6.2). The involvement eventually spread to larger areas, involving the segment or the entire lobe. The most common causes of bronchopneumonia include Staphylococcus aureus, Pseudomonas aeruginosa, Haemophilus influenzae, Escherichia coli, some fungi, and anaerobes. The appearance of bronchopneumonia 

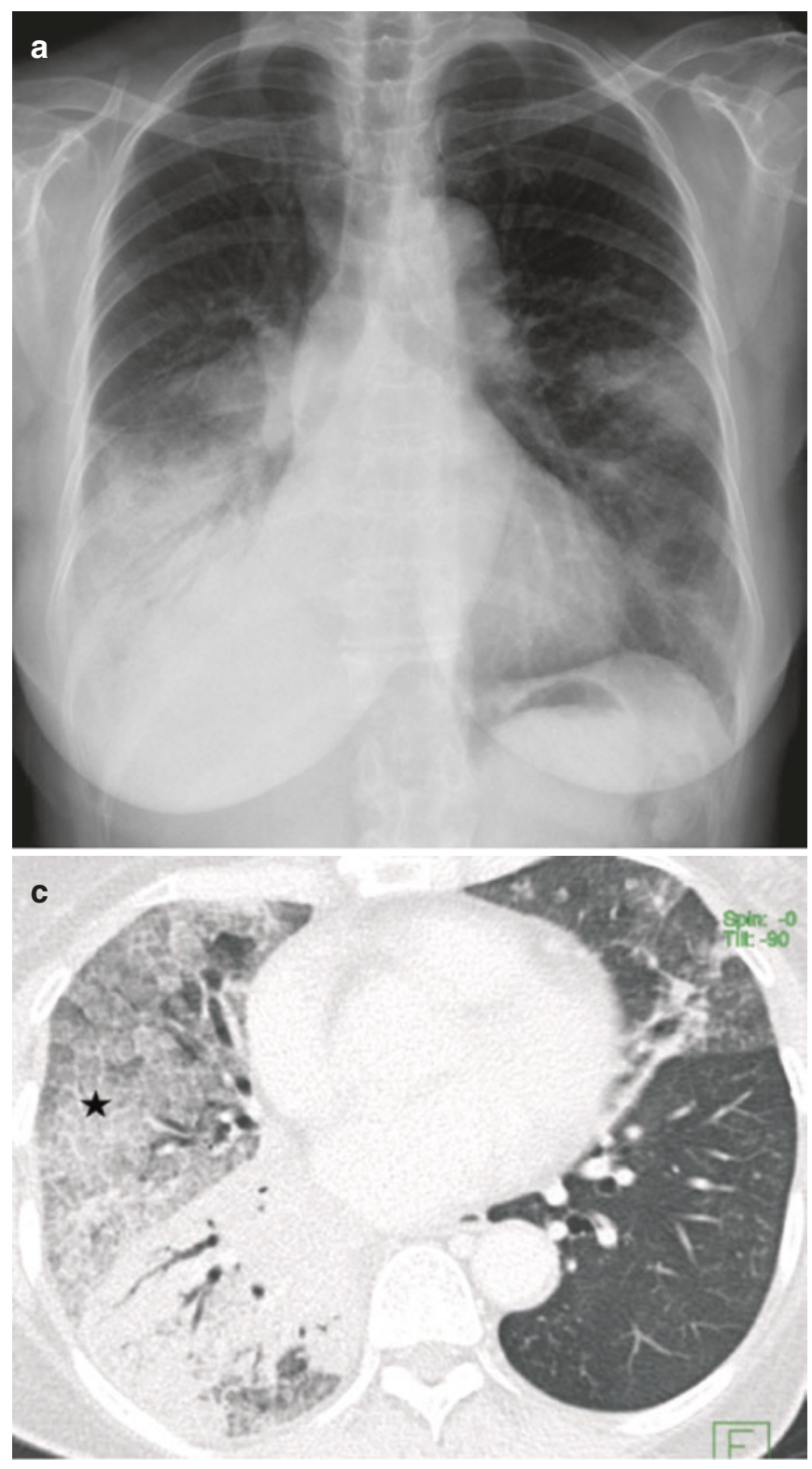

Fig. 6.1 Lobar pneumonia in a patient with Mendelson syndrome. (a) Frontal chest radiograph shows areas of consolidation in right mid- and lower zones and left midzone. (b, c) Axial CT images show consolida-

on radiograph depends upon the stage and may range from multifocal ground-glass opacities to consolidations. The opacities are usually asymmetric in distribution and may predominantly involve the lung bases. The pattern is better appreciated on computed tomography (CT) scans. Usual CT features include focal bronchial wall thickening, centrilobular nodularity, and multifocal opacities around the bronchioles, which can also be associated with tree-in-bud appearance [5]. With the progression of infection, the ground-glass opacities lead to confluent areas of consolida-

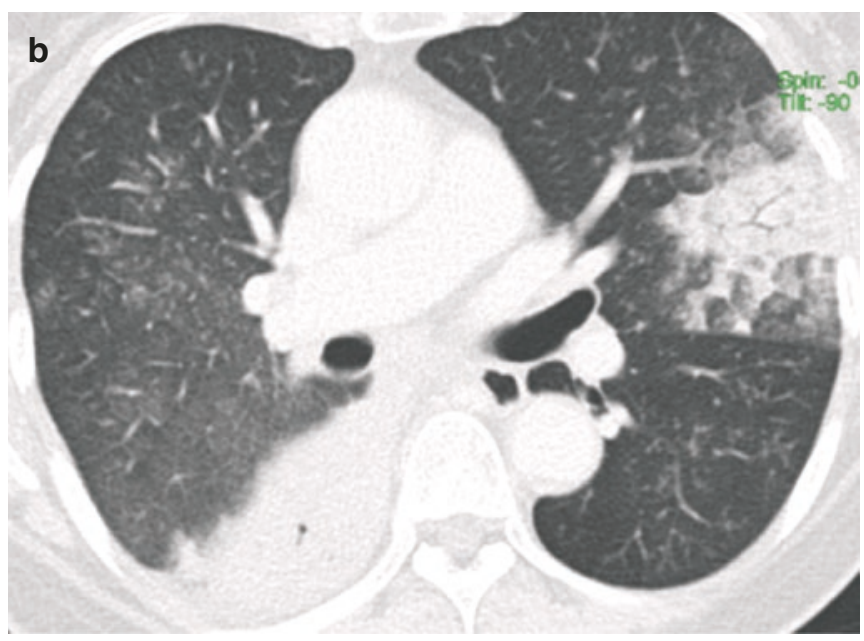

tion with "air bronchograms" in the left upper lobe and right lower lobe along with "crazy-paving" pattern in the right middle lobe (asterisk)

tion, and in most of the cases, CT shows scattered foci of the combination of two opacities.

\subsubsection{Ground-Glass Opacities}

The term "ground-glass opacification" describes lung opacity through which the bronchovascular markings are still visible. This is much better appreciated on CT scans and can be seen in a number of lung pathologies including interstitial 

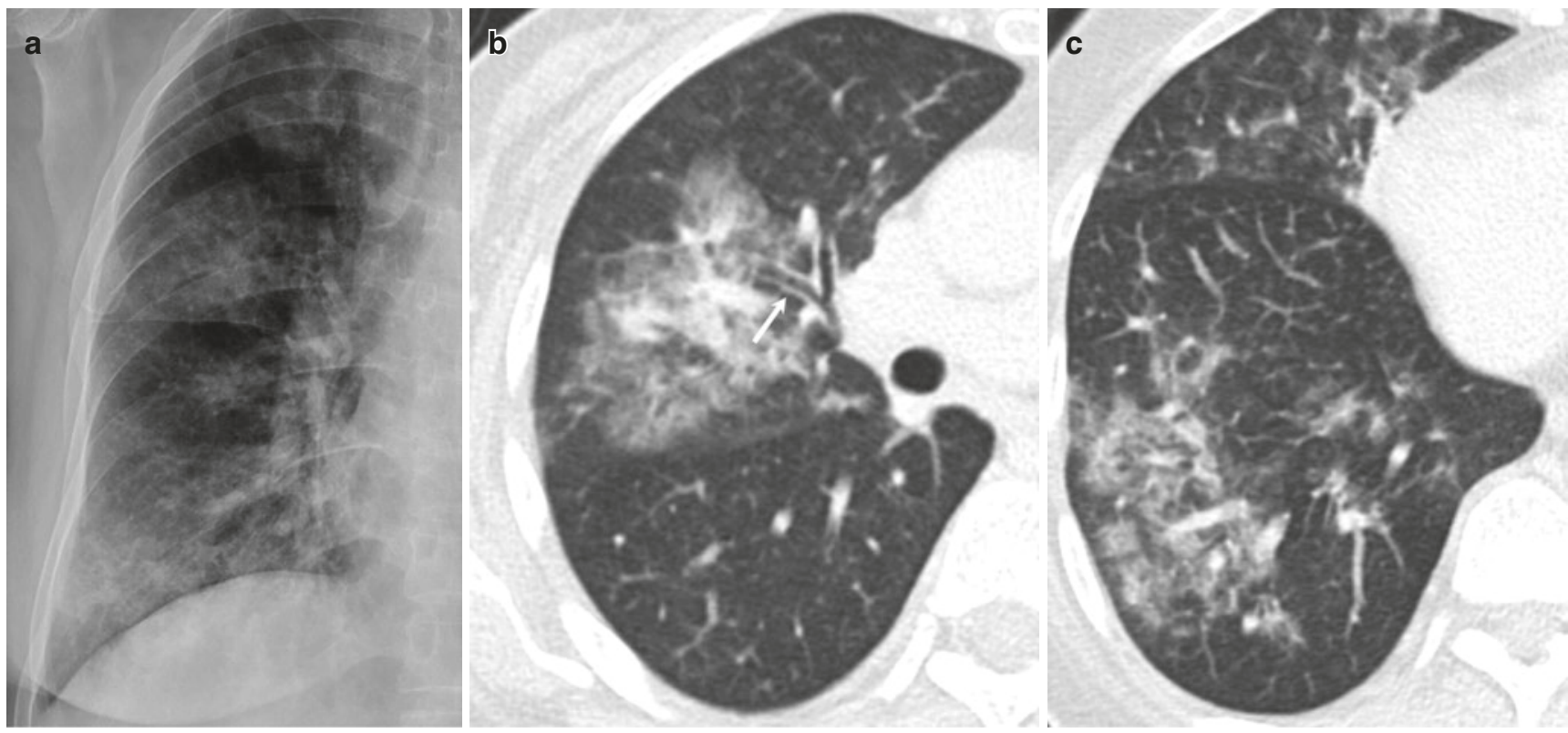

Fig. 6.2 Bronchopneumonia. (a) Chest radiograph shows patchy ground-glass opacities in the right lung. (b, c) Axial CT images show peribronchial ground-glass opacities with bronchial wall thickening (arrow)

Table 6.1 Lobar pneumonia patterns

\begin{tabular}{l|l}
\hline Cause & Imaging findings \\
\hline $\begin{array}{l}\text { Streptococcus } \\
\text { pneumonia }\end{array}$ & $\begin{array}{l}\text { Unilobar with usually no collapse or } \\
\text { cavitation, bulging fissures }\end{array}$ \\
\hline $\begin{array}{l}\text { Klebsiella } \\
\text { pneumonia }\end{array}$ & $\begin{array}{l}\text { Multilobar with lobar enlargement and often } \\
\text { with areas of cavitation. Bulging fissures } \\
\text { may be present }\end{array}$ \\
\hline $\begin{array}{l}\text { Staphylococcus } \\
\text { aureus } \text { pneumonia }\end{array}$ & $\begin{array}{l}\text { Consolidation with pleural effusion or even } \\
\text { empyema, pneumatoceles, or even } \\
\text { bronchopleural fistula. Commoner in } \\
\text { children }\end{array}$ \\
\hline $\begin{array}{l}\text { Pseudomonas } \\
\text { peruginosa }\end{array}$ & $\begin{array}{l}\text { Bilateral basal involvement with abscess } \\
\text { formation along with associated bronchial } \\
\text { wall thickening }\end{array}$ \\
\hline Primary tuberculosis & $\begin{array}{l}\text { Consolidation with collapse, more common } \\
\text { in the right lung particularly anterior } \\
\text { segment of the upper lobe }\end{array}$ \\
\hline
\end{tabular}

pneumonia [6]. This is due to cellular infiltrate in the alveolar septa and the peribronchovascular interstitium with resultant peribronchial and interlobular septal thickening or due to partial filling of airspaces in the lungs by exudate or transudate [1]. Predominant ground-glass opacification is usually seen in atypical pneumonia caused by Mycoplasma pneumonia and viral infections, particularly the opportunistic infections in an immunocompromised host [7]. These include Pneumocystis jiroveci pneumonia (PJP), cytomegalovirus (CMV) pneumonia, and herpes simplex virus (HSV) pneumonia. There are many other causes for ground-glass opacities, in immunocompromised hosts (Table 6.2).

\subsubsection{Nodules}

Lung nodules are less than $3 \mathrm{~cm}$, round to oval opacities that appear well-defined when surrounded by the normally aerated lung. They have a wide range of differentials ranging from infections, occupational lung diseases, malignancies, and immunological disorders. Solitary nodules can be seen in infections like tuberculosis, histoplasmosis, and hydatid disease. Multiple lung nodules can have centrilobular, perilymphatic (around fissures, peribronchovascular and subpleural), or random distribution [8]. These are discussed in the chapter of imaging of nodular lung diseases.

Nodules may demonstrate secondary changes like calcification and cavitation or can have surrounding ground-glass opacities. Cavitation is frequently seen in nosocomial infections and in immunocompromised hosts [9]. Some common causes of infective nodules include tuberculosis, nocardiosis, angioinvasive aspergillosis, cryptococcal infection, and atypical mycobacterial infection [1]. Miliary pattern, i.e., diffuse nodules less than $3 \mathrm{~mm}$, can be seen in a number of infections. Septic pulmonary embolism should always be considered in cases of cavitary pulmonary nodules (Fig. 6.4). This condition results from embolization of infectious particles in the lungs, which block the peripheral pulmonary artery divisions, resulting in infarction and necrosis of the lung parenchyma. Common sources of septic emboli include infectious tricuspid endocarditis (especially in intravenous drug abusers), peripheral thrombophlebitis, infected central line, and cardiac pacemaker [10]. Although not a reliable 

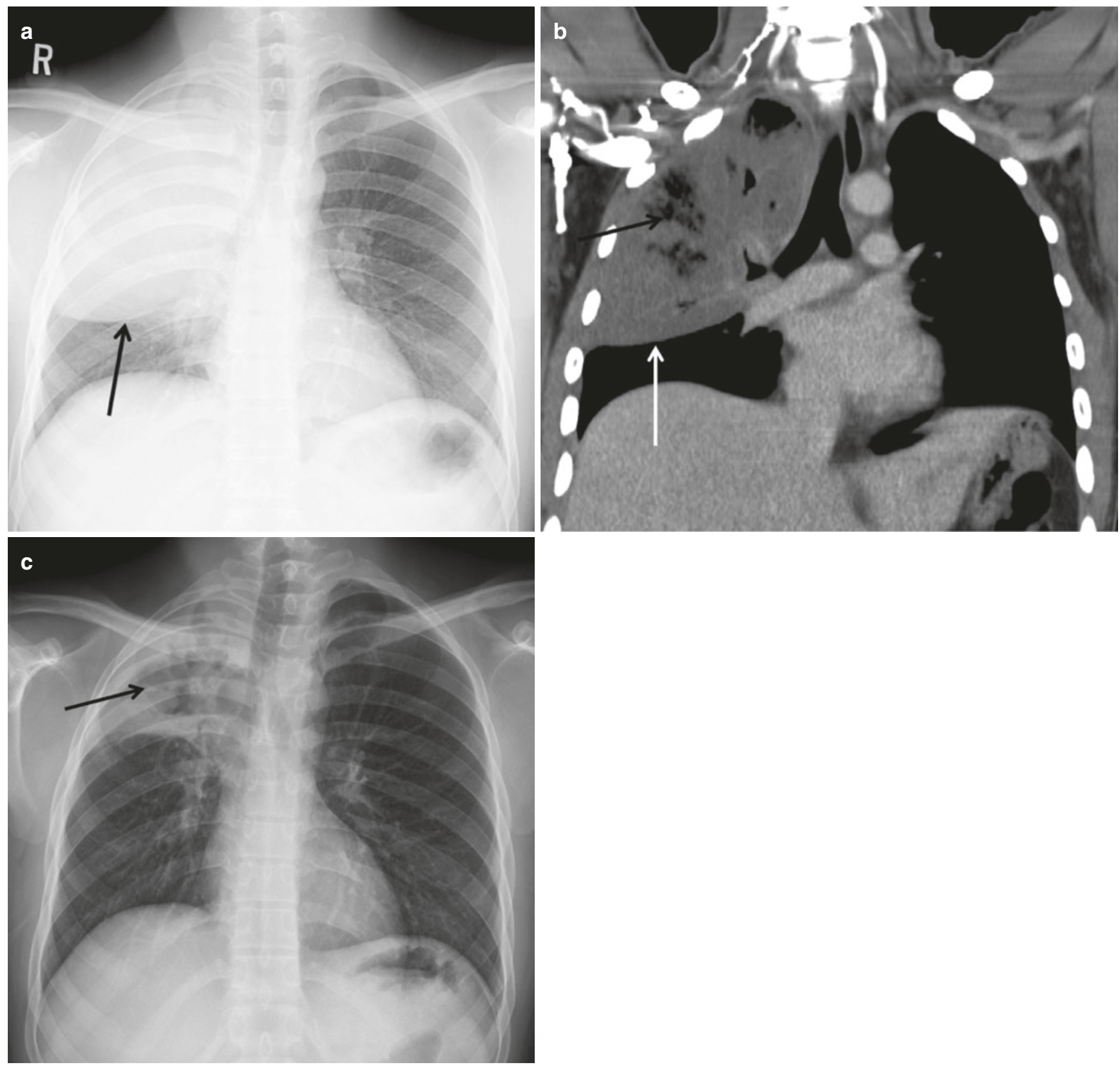

Fig. 6.3 Klebsiella pneumonia in a 35-year-old man, presenting with high-grade fever, rigors, cough, and high total white blood cell count. (a) Frontal chest radiograph shows a large homogeneous dense opacity in the right upper hemithorax with sagging inferior border (black arrow). (b) Corresponding coronal CT image demonstrates necrotiz-

sign, feeding vessels leading to the cavitary nodule can be demonstrated on CT images [11]. Ground-glass changes surrounding lung nodules can also be due to surrounding hemorrhage and have been described in viral infections, atypical mycobacterial infection, and candida infection [12, 13, 14]. Nodules with surrounding ground-glass changes and subpleural wedge-shaped opacities are highly suggestive of angioinvasive aspergillosis, in a context of severe neutropenia.

ing consolidation (black arrow) in the right upper lobe with "bulging fissure" (white arrow). (c) Follow-up radiograph after treatment shows residual scarring in the right upper lung (black arrow). "Bulging fissure" is a characteristic but not specific sign of Klebsiella pneumonia

\subsubsection{Cavities}

Lung cavities are thick-walled, gas-filled areas within the lung usually in a mass, area of consolidation, or even within a nodule. Bacterial infections can result in cavities as a complication of pneumonia, also termed as cavitating pneumonia. Lung abscess is a lesion within the lung with a collection of pus, usually seen in elderly, malnourished, or immunocompromised patients. Chest radiograph usually shows lung 
Table 6.2 Infectious causes of ground-glass opacities in an immunocompromised host

\begin{tabular}{l|l}
\hline Cause & CT findings \\
\hline PJP (AIDS) & $\begin{array}{l}\text { Ground-glass opacities in midzones } \\
\text { and perihilar distribution, peripheral } \\
\text { sparing, may be associated with } \\
\text { reticular opacities, nodules, } \\
\text { pneumatoceles, or even } \\
\text { consolidation }\end{array}$ \\
\hline $\begin{array}{l}\text { HSV pneumonia } \\
\text { (immunocompromised and } \\
\text { mechanically ventilated } \\
\text { patients) }\end{array}$ & $\begin{array}{l}\text { Ground-glass opacities with mild } \\
\text { bronchial dilatation and areas of } \\
\text { consolidation }\end{array}$ \\
\hline $\begin{array}{l}\text { CMV pneumonia } \\
\text { (especially following stem } \\
\text { cell or solid organ } \\
\text { transplant, AIDS) }\end{array}$ & $\begin{array}{l}\text { Ground-glass opacities with lobar } \\
\text { consolidation, miliary nodules, often } \\
\text { with surrounding halo, irregular } \\
\text { reticular opacities }\end{array}$ \\
\hline
\end{tabular}

opacity with or without an air-fluid level. CT with intravenous contrast is diagnostic, with a demonstration of thickwalled, rim-enhancing lesion, containing air-fluid level, within an area of consolidation (Fig. 6.5). Larger abscesses seldom respond to antibiotic treatment, usually need percutaneous or surgical drainage, and despite that have higher associated mortality rates.

\subsubsection{Pneumatoceles}

Pneumatoceles are air-filled cystic spaces within the lung sequel to pneumonia, trauma, or aspiration and are almost always asymptomatic. Pneumatoceles can be confused with abscesses; important differentiating features include smooth
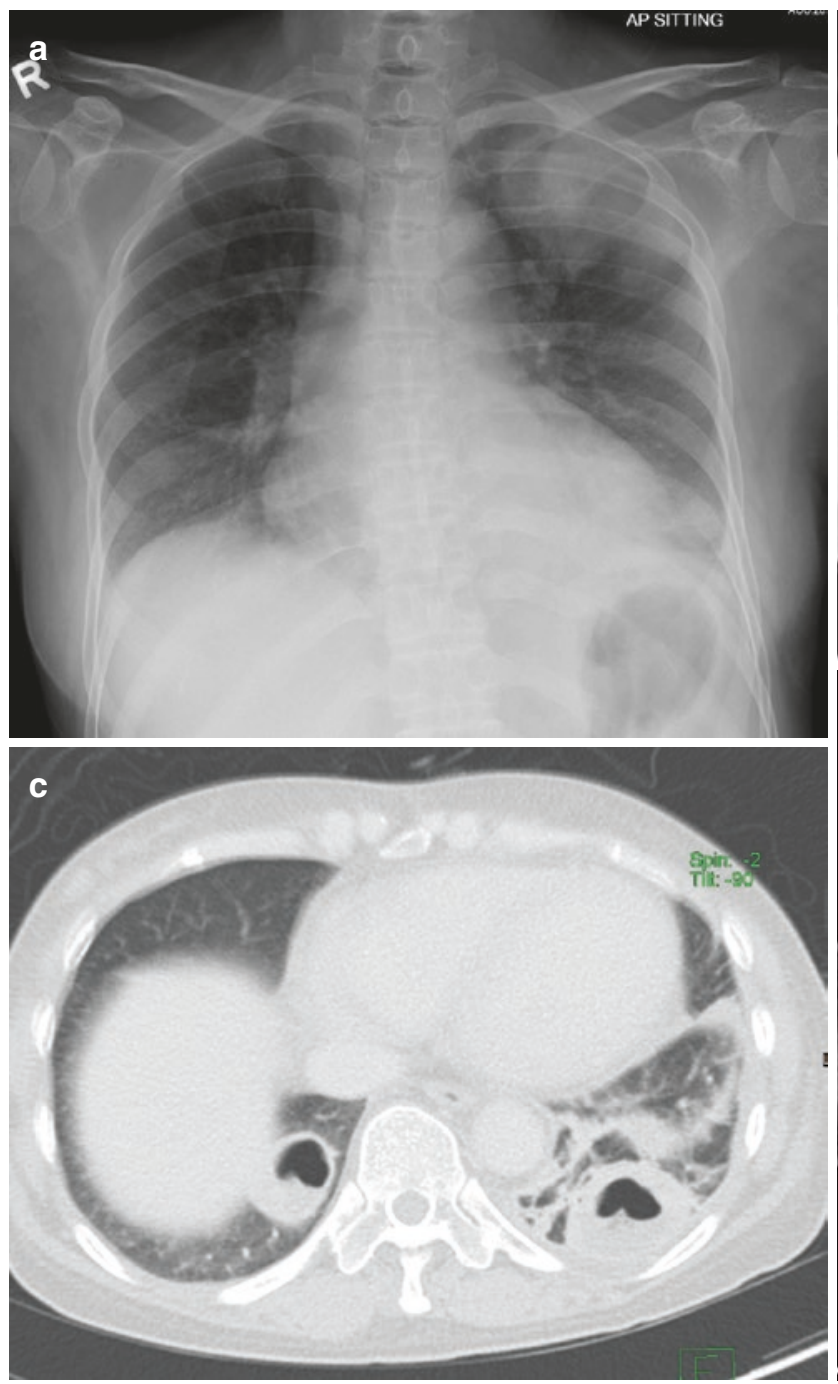

Fig. 6.4 Septic pulmonary emboli in an elderly female patient. (a) Frontal chest radiograph shows mass-like left upper zone opacity with left lower zone consolidation and effusion. $(\mathbf{b}, \mathbf{c})$ Axial CT lung win-
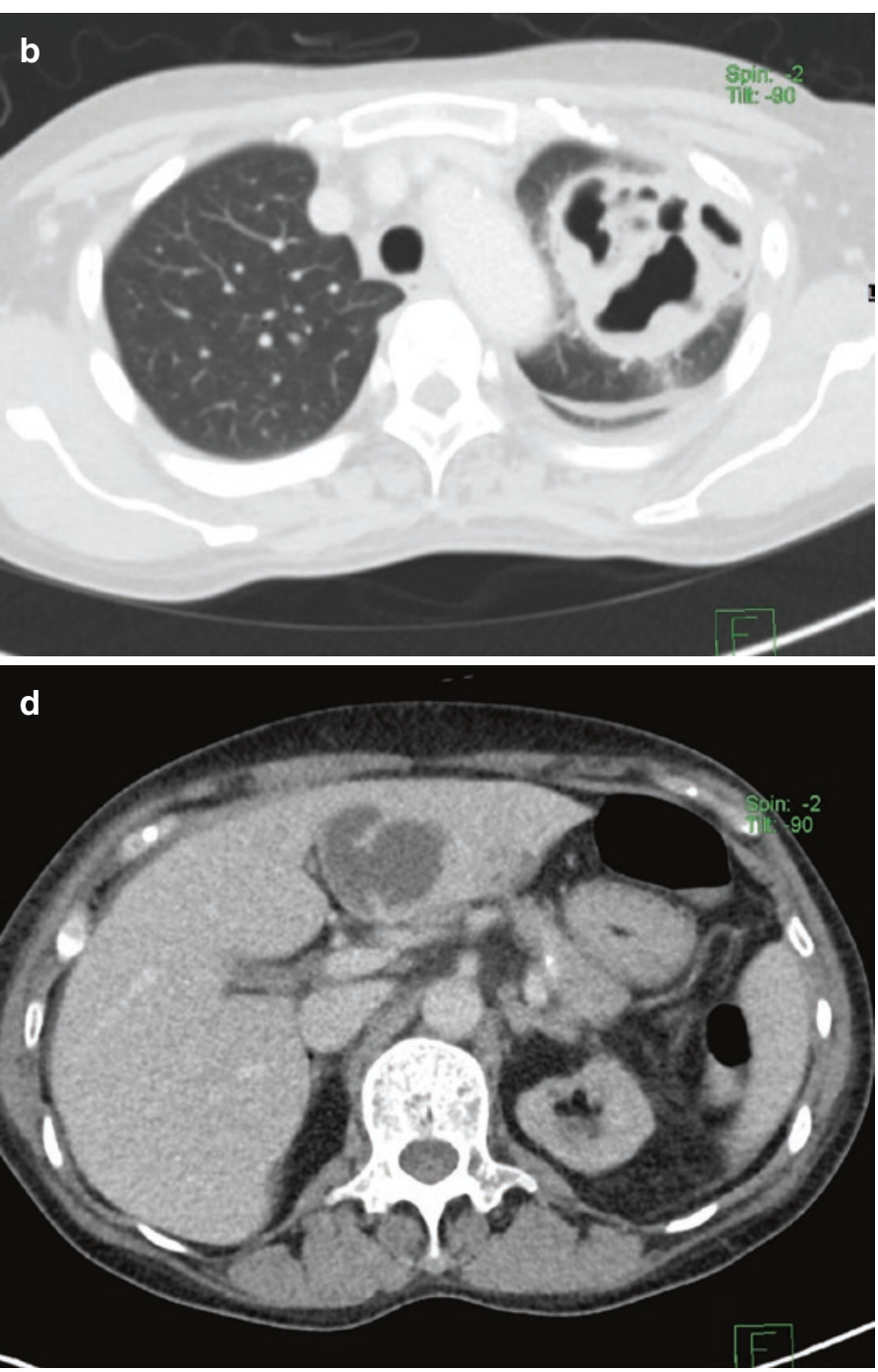

dow images show cavitary nodules and masses. (d, e) Axial and sagittal CT images of the liver show a left lobe liver abscess with thrombophlebitis of the hepatic vein branch (white arrow) 


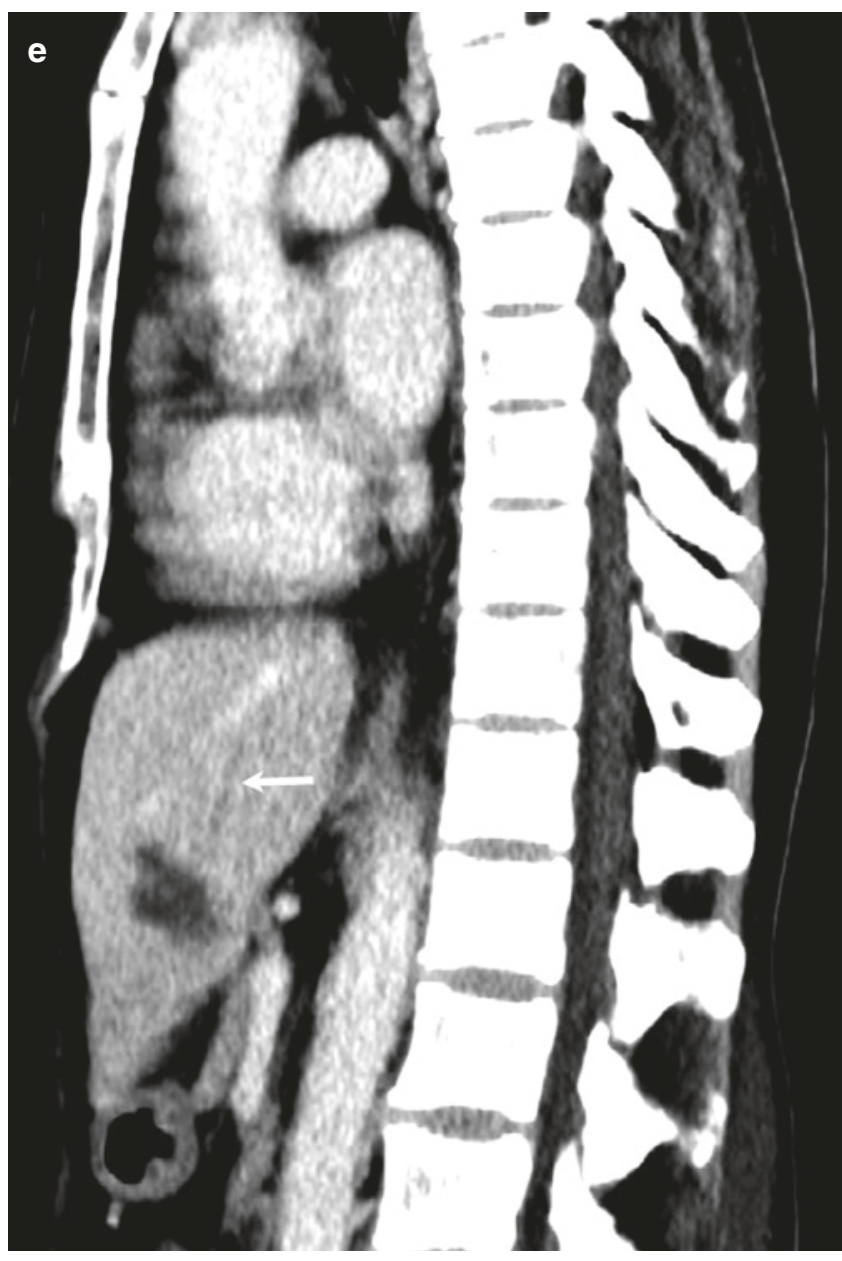

Fig. 6.4 (continued)

inner margins, thin wall, minimal fluid content, and usually asymptomatic course.

\subsection{Associated Findings}

Pulmonary infections are frequently associated with a number of ancillary findings like pleural effusion, pleural thickening, empyema, mediastinal lymphadenopathy, or even bone destruction. Simple parapneumonic effusions without associated pleural thickening usually respond to medical treatment; however loculated effusions and empyema typically need percutaneous drainage. Lung infections can present with enlargement of the hilar and the mediastinal nodes. Contrast-enhanced CT can not only identify enlarged nodes but can also characterize internal appearance and guide biopsy.
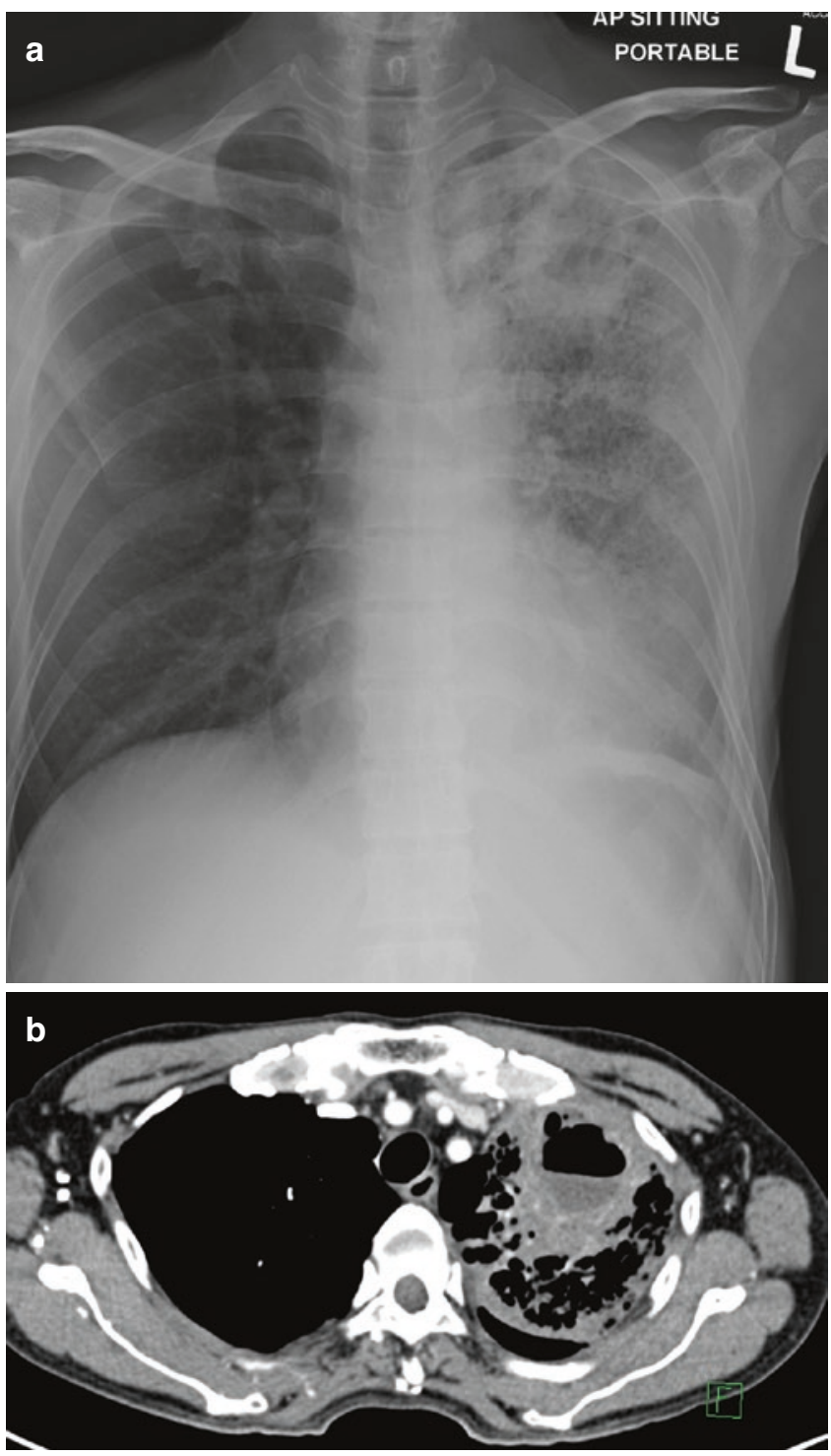

Fig. 6.5 Lung abscess in an elderly patient. (a) Frontal chest radiograph shows extensive left lung opacities with an air-fluid level in lesion. (b) Axial CT image demonstrates the thick-walled abscess with surrounding lung changes

\subsection{Infections}

\subsubsection{Tuberculous}

Tuberculosis is a granulomatous infection caused by Mycobacterium tuberculosis, a rod-shaped aerobic bacterium. It is a global health problem, common in developing Southeast Asian and African countries. Historically, pulmonary tuberculosis is classified into two subtypes: primary and 
post-primary tuberculosis. Primary tuberculosis patients have no previous exposure and, usually, develop active disease within 2 years of infection. Post-primary tuberculosis is also known as reactivated tuberculosis, seen in patients who have had a previous infection. It is more commonly endogenous reactivation rather than due to superinfection (exogenous). Clinical presentation of tuberculosis varies with age and the immune status of the patient, with a cough, lowgrade fever, anorexia, and loss of weight being the usual presenting complaints. There are no well-established criteria on imaging for the two subtypes of pulmonary tuberculosis. The role of imaging is to assess the disease burden, the presence of cavities, and complications of tuberculosis (Figs. 6.6, 6.7, 6.8, and 6.9).

\subsubsection{Primary Tuberculosis}

Primary tuberculosis occurs most commonly in children but is being seen with increasing frequency in adults. There are three main components of primary tuberculosis: parenchymal focus, lymphadenopathy, and pleural effusion (Table 6.3). The parenchymal focus is typically unilateral airspace consolidation due to bronchoalveolar caseous exudate. The parenchymal focus called "Ghon focus" usually resolves without any sequel on chest radiograph or less commonly heals by calcification or calcified granuloma $[15,16]$. In a small number of cases, the infection progresses with enlargement of the parenchymal lesion and spread of infection along the lymphatics in the mediastinal lymph nodes. Majority of the cases of childhood primary tuberculosis in the endemic zones have dominant lymphadenopathy, a finding less commonly seen in adults. "Ranke complex" is suggestive of previous tuberculous infection and compromises of Ghon focus with calcification in the hilar node. Pleural involvement is seen in few cases, usually the same side as the parenchymal disease [17]. Historically, the cavities are considered as a hallmark of post-primary tuberculosis but are increasingly recognized in adults with primary tuberculosis.

\subsubsection{Post-Primary or Reactivation Tuberculosis}

Post-primary tuberculosis usually involves the apical and posterior segments of the upper lobe and the superior segment of the lower lobe, explained by relatively poor lymphatic drainage and higher oxygen tension [18] (Table 6.4). Most cases involve more than one segment, in many cases even showing bilateral disease. Cavitation may be present in almost up to $50 \%$ of cases of post-primary tuberculosis. The endobronchial spread of the disease occurs when the caseous necrosis liquefaction communicates with the bronchial tree, resulting in nodular lesions distant to the cavity. This results in classical "tree-in-bud" opacities on CT scan, compromising of tiny centrilobular nodules, and branching linear opacities [19]. Tuberculoma can be solitary or multiple, round, oval, or elongated nodules and appear hyperdense or demonstrate frank areas of peripheral calcification. Pleural disease and chest wall involvement are less common and seen only in a minority of the cases.

Lung cavities and bronchiectasis are late complications of pulmonary tuberculosis, usually seen in the apical and posterior segments of the upper lobes. A characteristic CT feature of the tubercular cavity is its communication with the tracheobronchial tree. Secondary colonization of a tuberculous cavity by Aspergillus can result in the formation of a fungal ball. CT imaging demonstrates air surrounding an intracavitary mass, also known as the "air crescent sign" [20]. Tuberculosis can also extend into the trachea and the bronchial tree, leading to scarring and bronchostenosis [21]. The infection can spread from the pleural space to the soft tissues of the chest wall, resulting in chest wall abscess also known as "empyema necessitans" [22]. Rasmussen aneurysm is a pseudoaneurysm that arises within or adjacent to a tuberculous cavity. It is a rare complication and results due to the weakening of the inflamed wall of a pulmonary artery branch (Fig. 6.10).

\subsubsection{Miliary Tuberculosis}

Miliary tuberculosis can be seen in both primary and postprimary tuberculosis and is due to hematogenous dissemination of the infection. Chest radiographs can be unremarkable until advanced disease, where it can show small nodules extensively involving the lung fields. CT is diagnostic with 1-3 mm nodules with or without associated interlobular septal thickening, identifiable on high-resolution computed tomography (HRCT) (Fig. 6.11).

\subsubsection{Nontuberculous Mycobacterial Infection}

Nontuberculous mycobacteria (NTM) infections were confirmed to be true human pathogens only by 1950 and were later shown to be very similar to post-primary tuberculosis by Christensen et al., in the 1970s [23]. The organisms causing most of the NTM infections include $M$. aviumintracellulare (MAC) (approx. 60\%) and M. kansasii (about $25 \%$ ) with other less common organisms being $M$. xenopi, M. szulgai, M. fortuitum, M. abscessus, and M. gordonae $[23,24]$. "Lady Windermere" syndrome is a typical pattern 


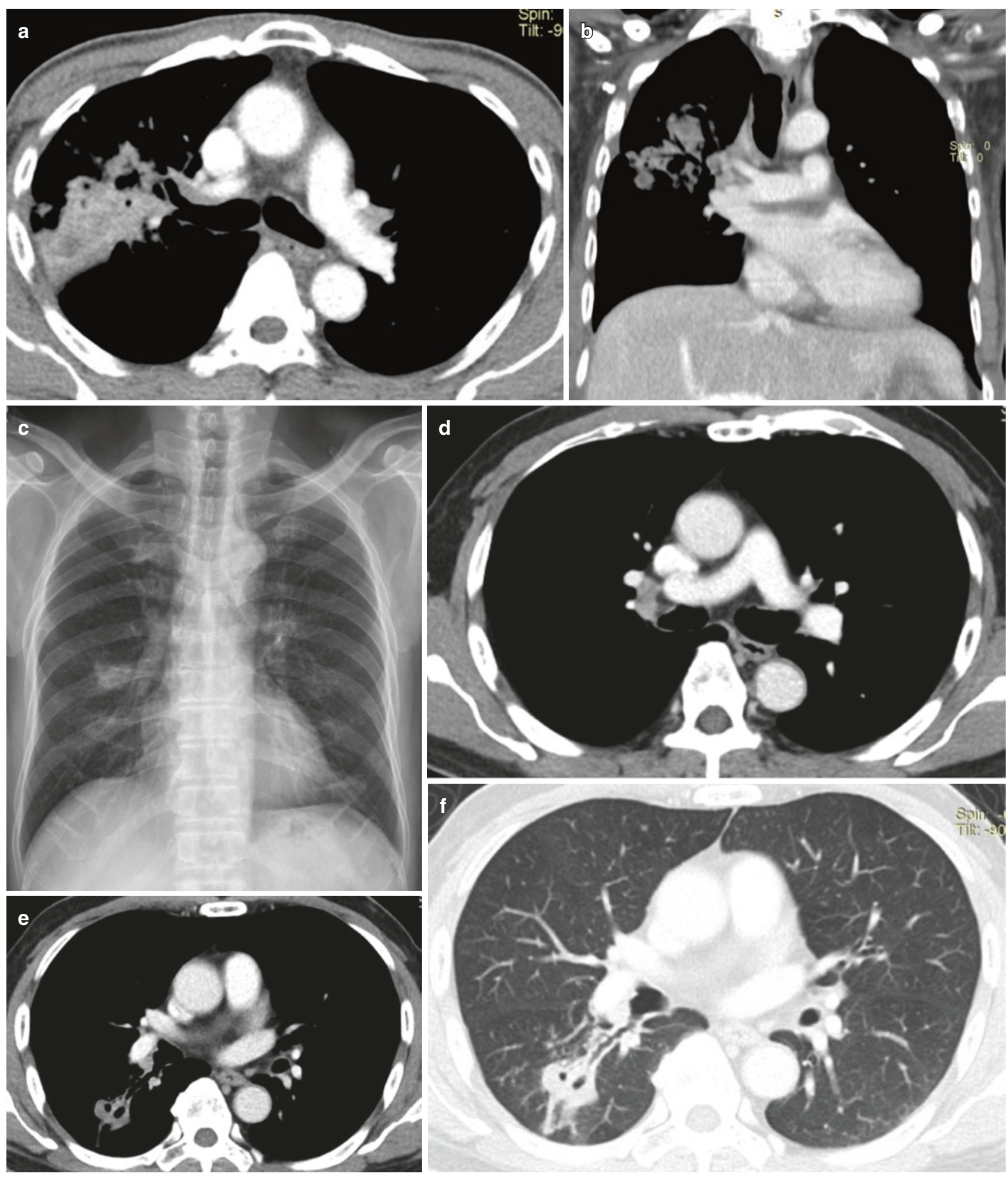

Fig. 6.6 Primary tuberculosis in an adult. (a, b) Axial and coronal CT images show heterogeneous consolidation in the right upper lobe with hilar lymph nodes. Post-primary tuberculosis in another patient. (c) Frontal chest radiograph shows a cavitary nodule in the right midzone. (d-f) Axial CT images show a thick-walled cavitary nodule in the superior segment of the right lower lobe communicating with the airway and right hilar node 

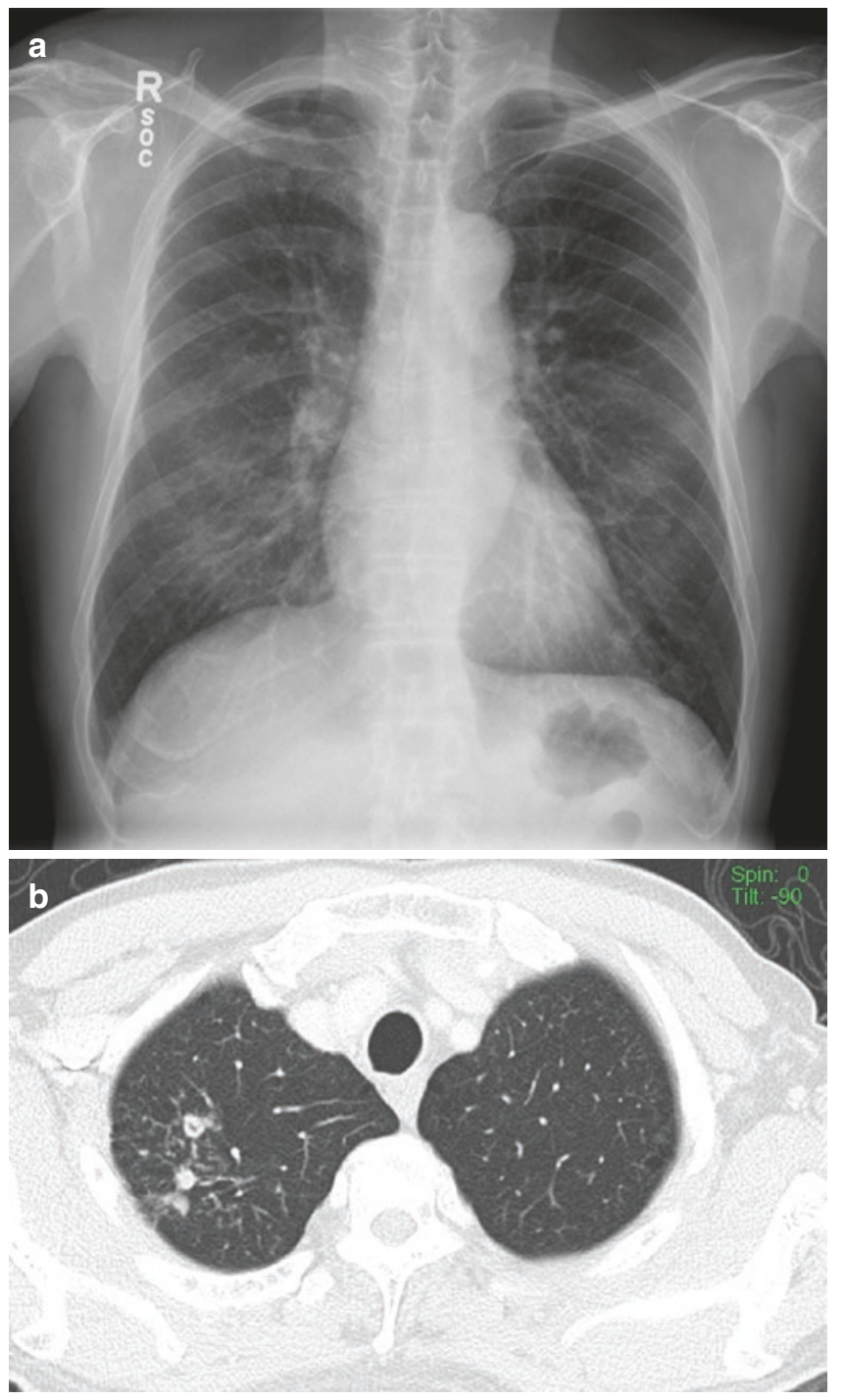

Fig. 6.7 A 30-year-old asymptomatic man for a pre-employment checkup. (a) Frontal chest radiograph shows small nodules in the right upper zone. (b) Axial CT image shows granulomas with tree-in-bud opacities in the right upper lobe. These were presumed to be sequel to primary tuberculosis

of MAC infection in an elderly woman characterized by bronchiectasis, tree-in-bud opacities, centrilobular nodules, and eventual chronic atelectasis of the right middle lobe and lingula. The CT features of NTM are described in Table 6.5 (Figs. 6.12 and 6.13). Diagnosis of these infections is difficult as these organisms often colonize the airways and a positive culture is not diagnostic of an infection. Invasive measures like bronchoalveolar lavage and transbronchial biopsy are often needed for confirming the diagnosis.

There can be a disseminated pattern of nontuberculous mycobacterial infection in patients who are immunocompro-
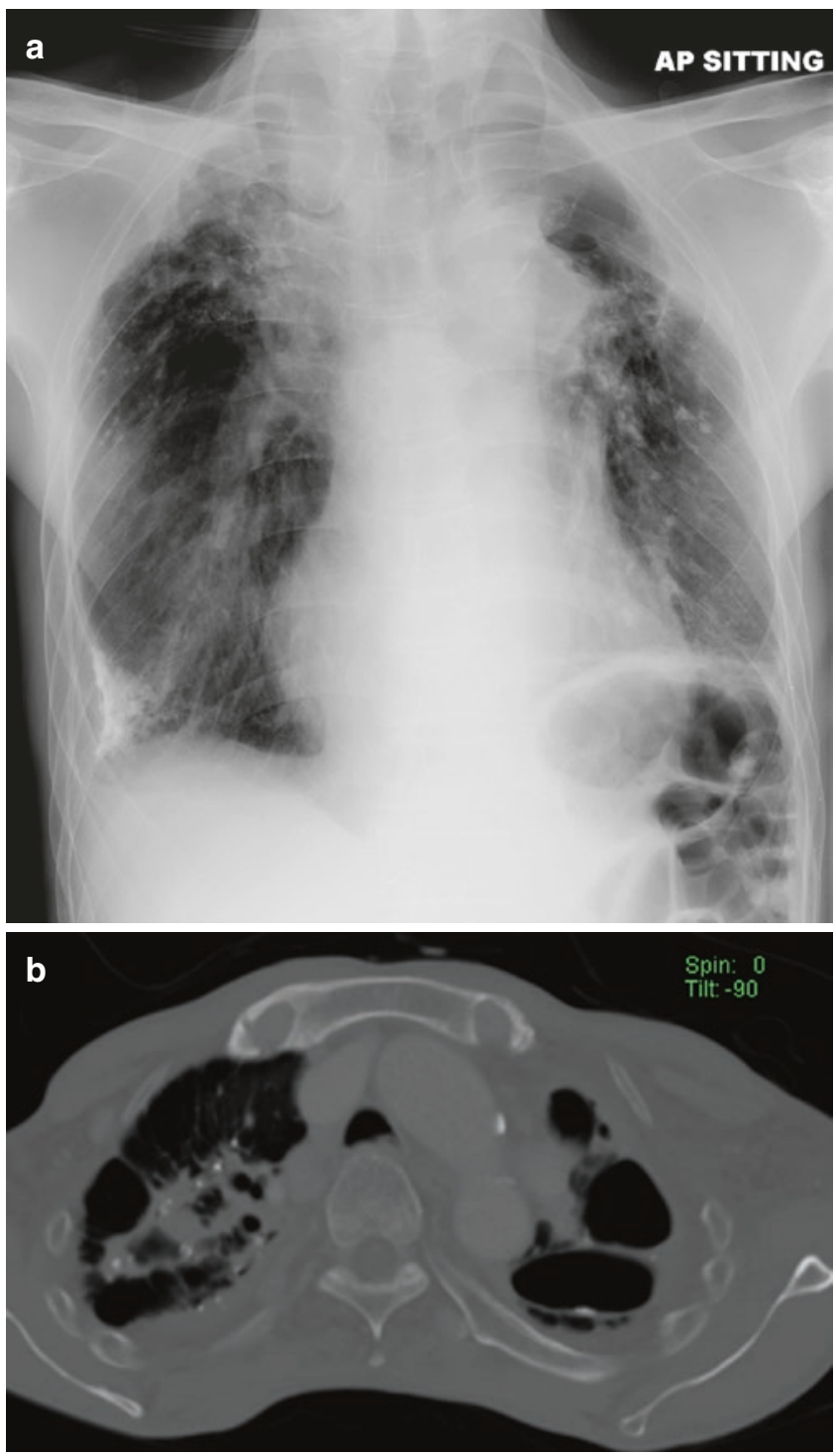

Fig. 6.8 Features of old tuberculosis. (a) Frontal chest radiograph shows extensive bilateral scarring, calcified nodules, volume loss, and pleural calcification (from previous empyema). (b) Axial CT image in the bone window shows calcified lung nodules, surrounding patchy consolidation and destruction of the left upper lobe lung parenchyma with cavity formation

mised [25]. MAC is the most common organism for atypical mycobacterial infection in AIDS (acquired immune deficiency syndrome). These infections usually occur with low CD4 counts of below 100 cells $/ \mathrm{mm}^{3}$. The diagnosis is difficult on imaging as these infections coexist with a number of other opportunistic lung infections. The most common imaging feature is mediastinal lymphadenopathy, followed by airspace opacities, miliary lung nodules, and pleural effusion [26]. Nontuberculous mycobacterial infections can also be 

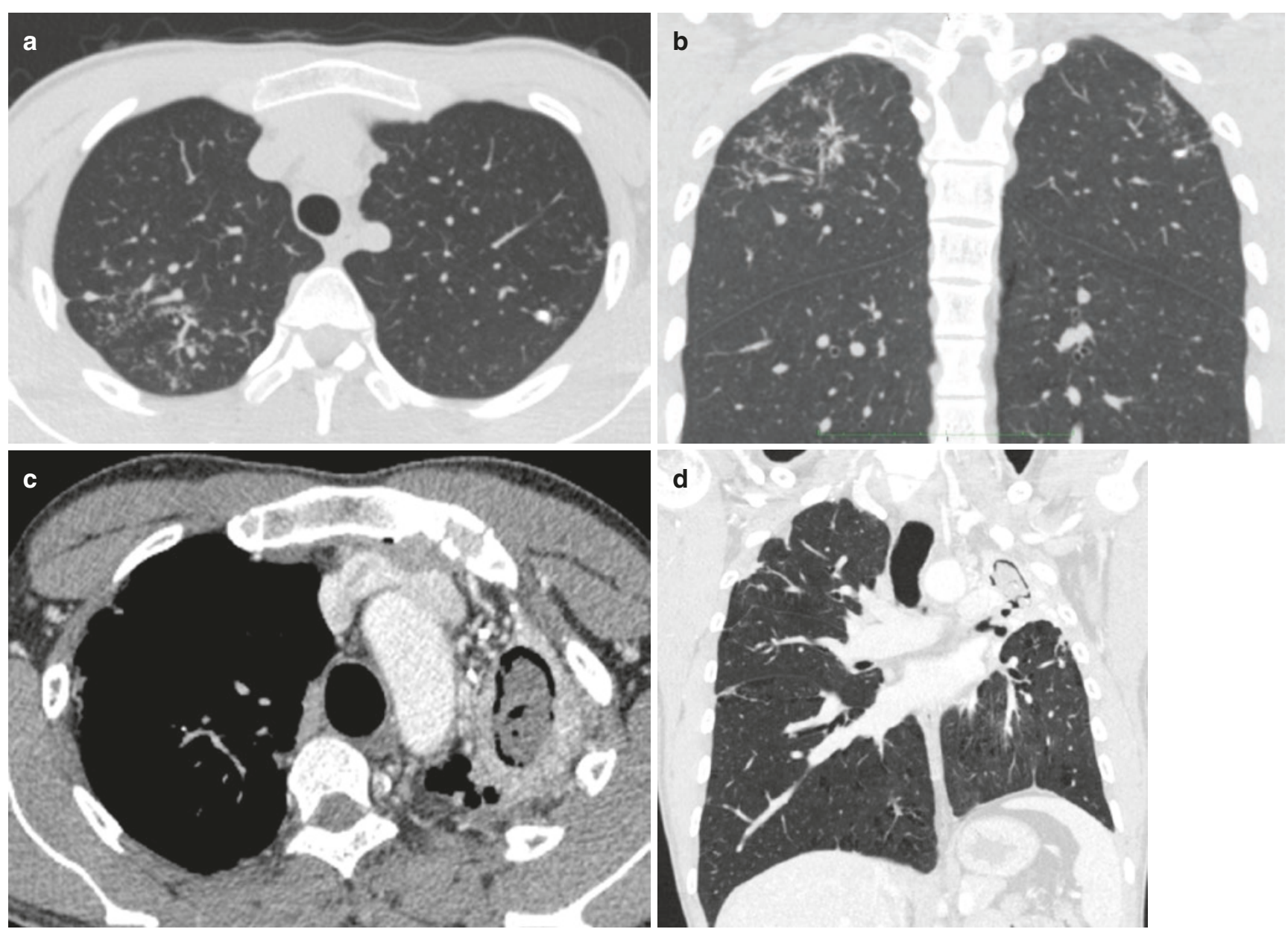

Fig. 6.9 Tree-in-bud opacities in a sputum-positive case of tuberculosis. (a, b) Axial and coronal CT images show tree-in-bud opacities in upper lobes. Fungal ball in another patient presenting with hemoptysis.

(c, d) Axial and coronal CT images show a tubercular cavity with a softtissue mass surrounded by an air crescent. Note the increased vascularity around the cavity

Table 6.3 Imaging features of primary tuberculosis

\begin{tabular}{l|l}
\hline Chest radiograph & CT findings \\
\hline $\begin{array}{l}\text { Dense airspace } \\
\text { consolidation mainly } \\
\text { middle and lower lobes }\end{array}$ & $\begin{array}{l}\text { Homogeneous, dense consolidation, } \\
\text { sometimes linear, nodular, patchy, or } \\
\text { even like a mass } \\
\text { Mass rarely show cavitation }\end{array}$ \\
\hline Bulky hilum & $\begin{array}{l}\text { Enlarged hilar and mediastinal nodes, } \\
\text { showing central necrosis and peripheral } \\
\text { rim enhancement }\end{array}$ \\
\hline $\begin{array}{l}\text { Pleural effusion with or } \\
\text { without parenchymal } \\
\text { disease }\end{array}$ & $\begin{array}{l}\text { Pleural effusion with or without septa/ } \\
\text { nodularity, pleural thickening, air-fluid } \\
\text { level (post-drainage or bronchopleural } \\
\text { fistula) }\end{array}$ \\
\hline
\end{tabular}

seen in non-HIV immunocompromised cases, like patients on chemotherapy, post-organ transplantation, and long-term steroids and patients with lymphoma or leukemia [27, 28]. Radiographic findings are limited to reticulonodular opacities, cavities, and lymphadenopathy. There are reported cases of hypersensitivity pneumonitis caused by inhalation of MAC, most commonly from hot tub exposure [29].
Table 6.4 Imaging features of post-primary tuberculosis

\begin{tabular}{l|l}
\hline Chest radiograph & CT findings \\
\hline $\begin{array}{l}\text { - Patchy airspace opacities, } \\
\text { often in multiple areas, } \\
\text { even bilateral in some cases }\end{array}$ & $\begin{array}{l}\text { - Centrilobular nodules, mucoid } \\
\text { impaction of branching contiguous } \\
\text { bronchioles "tree-in-bud" pattern }\end{array}$ \\
\hline - Cavity formation & $\begin{array}{l}\text { - Area of cavitation, thick and } \\
\text { irregular walls, sometimes small } \\
\text { fluid level }\end{array}$ \\
\hline - Hilar lymphadenopathy & $\begin{array}{l}\text { - Thick wall cavity classically } \\
\text { communicating with the bronchial } \\
\text { tree }\end{array}$ \\
\hline $\begin{array}{l}\text { Round to oval nodule } \\
\text { (tuberculoma) surrounded by } \\
\text { satellite smaller nodules that may } \\
\text { have calcification }\end{array}$
\end{tabular}

\subsubsection{Fungal Infections}

Fungal lung infections can be seen in both immunocompromised and immunocompetent hosts. Infections in immunocompromised patients range from Aspergillus, cryptococci, 

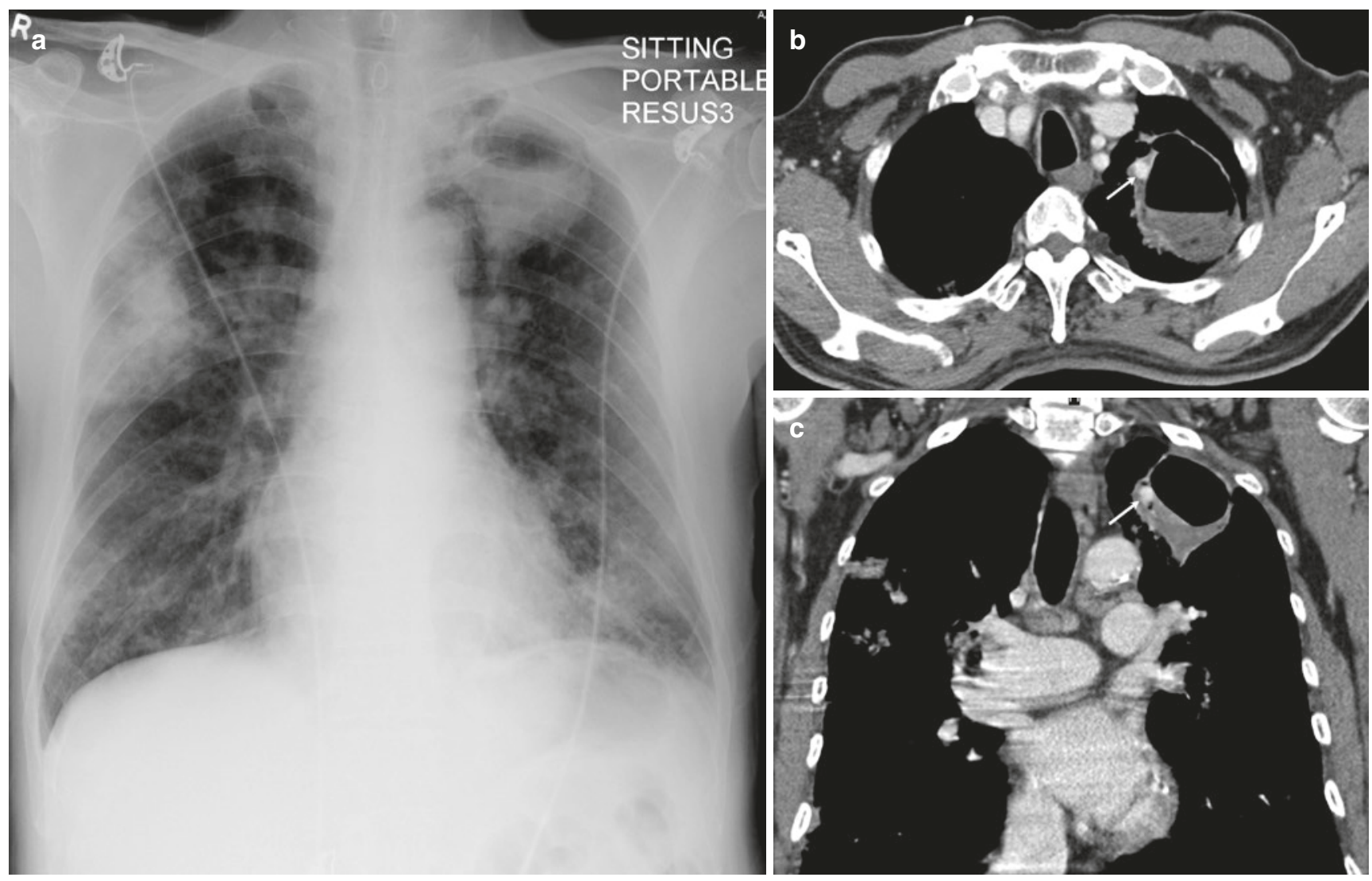

Fig. 6.10 Rasmussen aneurysm in an elderly patient with tuberculosis. (a) Frontal chest radiograph shows left upper zone opacity with an airfluid level and areas of consolidation in both lungs. (b, c) Axial and coronal CT images show an enhancing aneurysm (white arrows) along the medial aspect of the cavity

\subsubsection{Candidiasis}

Candidiasis is most commonly caused by Candida albicans, and lung infection is usually seen in immunocompromised patients, usually associated with widespread disease involving multiple organs. The imaging features of pulmonary candida infection are described in Table 6.7.

\subsubsection{Coccidioidomycosis}

This infection is caused by the dimorphic fungus Coccidioides immitis and is endemic in parts of southwestern America and Mexico. Chest radiographs in the acute stage are usually unremarkable, sometimes showing areas of consolidation and bulky hilum (node enlargement). Solitary or multiple nodules with cavities can be seen in the chronic stage of the infection, better assessed on CT scans, the nodules more commonly involving the lung bases [33] (Fig. 6.14). Cavities can be with thin ("grape-skin") or thick walls [34]. Disseminated disease in immunocompromised hosts usually shows diffuse reticulonodular or miliary pattern.

\subsubsection{Blastomycosis}

Pulmonary blastomycosis is caused by Blastomyces dermatitidis, usually seen as necrotizing granulomas, especially tures of pulmonary cryptococcosis are described in Table. 6.6. 

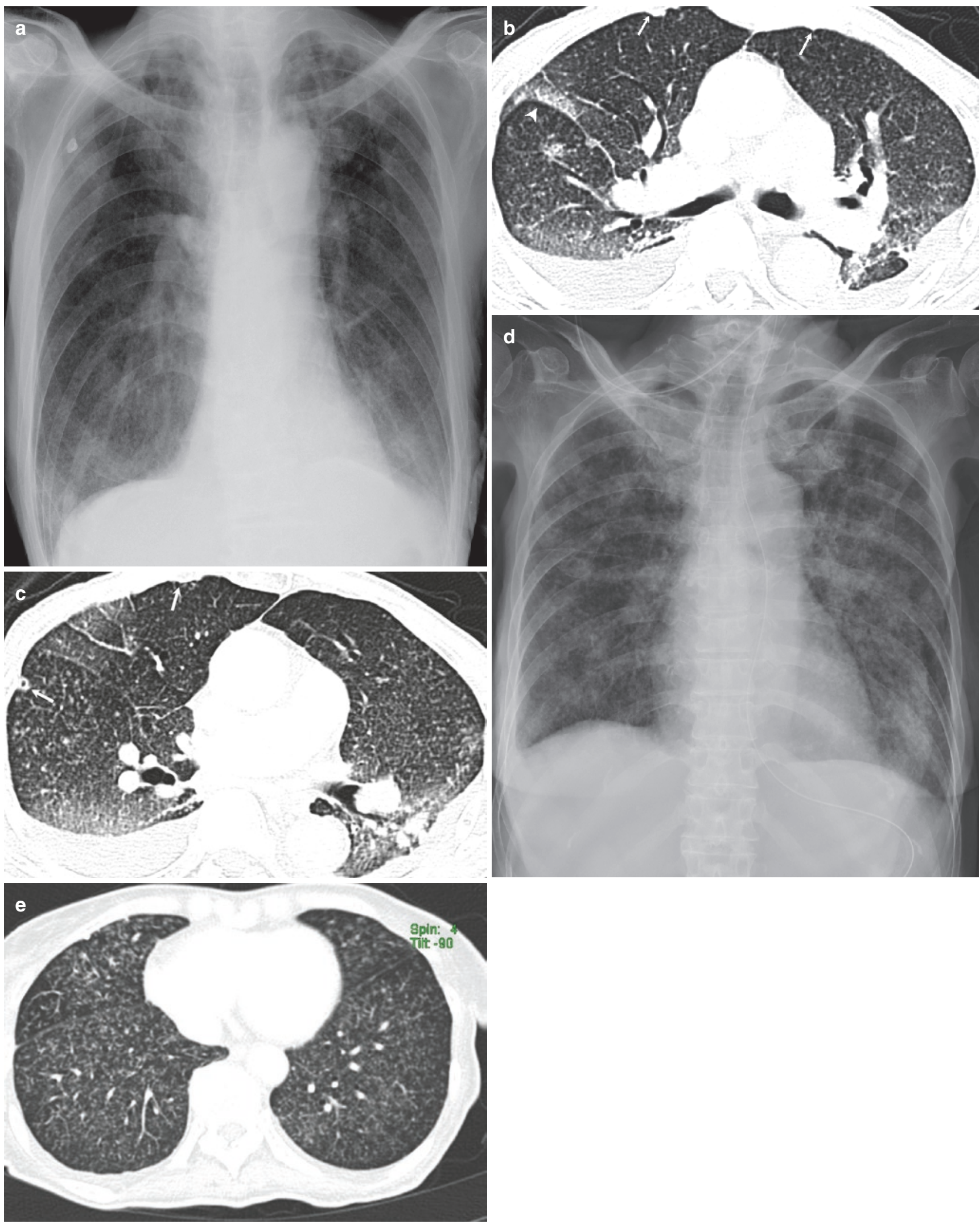

Fig. 6.11 Miliary tuberculosis. (a) Frontal chest radiograph shows numerous small nodules in both lungs. (b, c) Axial CT images in lung window show extensive randomly scattered miliary nodules including subpleural (white arrows) and fissural nodules (arrowhead). Another

case of extensive endobronchial spread of tuberculosis with (d) frontal chest radiograph showing numerous small nodules in both lungs and (e) axial CT image in lung window showing innumerable tiny centrilobular nodules with subpleural and fissural sparing 
suppurative type [30]. Imaging findings include patchy or confluent airspace consolidation, which may show associated cavitation. The other imaging feature is nodules or masses (Fig. 6.15). Disseminated infection results in a miliary pattern of involvement.

Table 6.5 Nontuberculous mycobacterial infection patterns

\begin{tabular}{l|l|l}
\hline & Cavitary or classic form & Bronchiectatic form \\
\hline Pattern & $\begin{array}{l}\text { Similar to post-primary } \\
\text { tuberculosis }\end{array}$ & $\begin{array}{l}\text { Coexistence of mosaic } \\
\text { pattern and } \\
\text { bronchiectasis is } \\
\text { highly suggestive }\end{array}$ \\
\hline Organisms & Usually MAC & MAC or M. kansasii \\
\hline Radiograph & $\begin{array}{l}\text { Cavitary lesion with the } \\
\text { endobronchial spread, } \\
\text { atelectasis, pleural } \\
\text { thickening }\end{array}$ & $\begin{array}{l}\text { Randomly distributed } \\
\text { nodular opacities }\end{array}$ \\
\hline CT & $\begin{array}{l}\text { Single cavity with } \\
\text { ill-defined margins, } \\
\text { bronchiectasis, pleural } \\
\text { thickening }\end{array}$ & $\begin{array}{l}\text { "Tree-in-bud" } \\
\text { opacities, cylindrical } \\
\text { bronchiectasis }\end{array}$ \\
\hline Demographics & $\begin{array}{l}\text { Elderly white patients } \\
\text { with underlying chronic } \\
\text { lung disease }\end{array}$ & Elderly white patients \\
\hline $\begin{array}{l}\text { Predominant } \\
\text { involvement }\end{array}$ & $\begin{array}{l}\text { Upper lobes } \\
\text { Eight middle lobe and }\end{array}$ \\
\hline
\end{tabular}

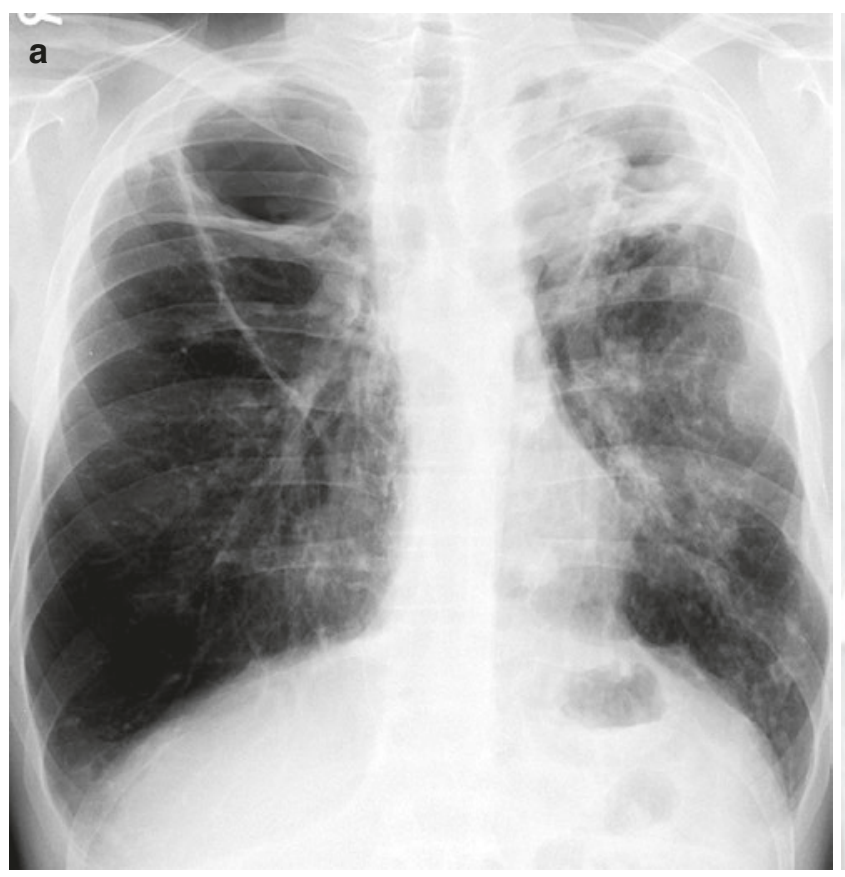

Fig. 6.12 Cavitary form of atypical mycobacterial infection in an elderly patient. (a) Frontal chest radiograph shows upper zone cavitary changes with background scarring and patchy opacities, more on the

\subsubsection{Aspergillosis}

Aspergillosis is usually caused by Aspergillus fumigatus, a fungus of the Aspergillus species. The lung infection is only seen when there is hypersensitivity or in patients with reduced immunity. Pulmonary aspergillosis is a term collectively used for a number of recognized forms of lung disease (Table 6.8), each having distinct clinical and imaging features (Figs. 6.16, 6.17, 6.18, and 6.19). Aspergilloma and allergic bronchopulmonary aspergillosis (ABPA) are the noninvasive forms of the disease. Chronic necrotizing aspergillosis (CNA) is the locally invasive form, seen in immunocompromised patients and those with the chronic pulmonary disease. Invasive aspergillosis is a grave disease, affecting immunocompromised and critically ill patients or those with chronic obstructive pulmonary disease [35].

Aspergilloma is also known as "fungal ball" and is most commonly seen in a tuberculous cavity (Fig. 6.16). It can also be seen in other cavity-forming conditions or less commonly in cystic bronchiectasis [2]. ABPA is a type of eosinophilic lung disease, usually seen in patients with long-standing asthma, cystic fibrosis, or Kartagener's syndrome. The disease has various clinical stages from acute stage to end-stage fibrosis, patients usually presenting with asthma-like presentation with a recurrent lung infection. Imaging features are included in the major diagnostic criteria of ABPA. Invasive aspergillosis is the commonest fungal infection involving the lungs [30], typically seen in

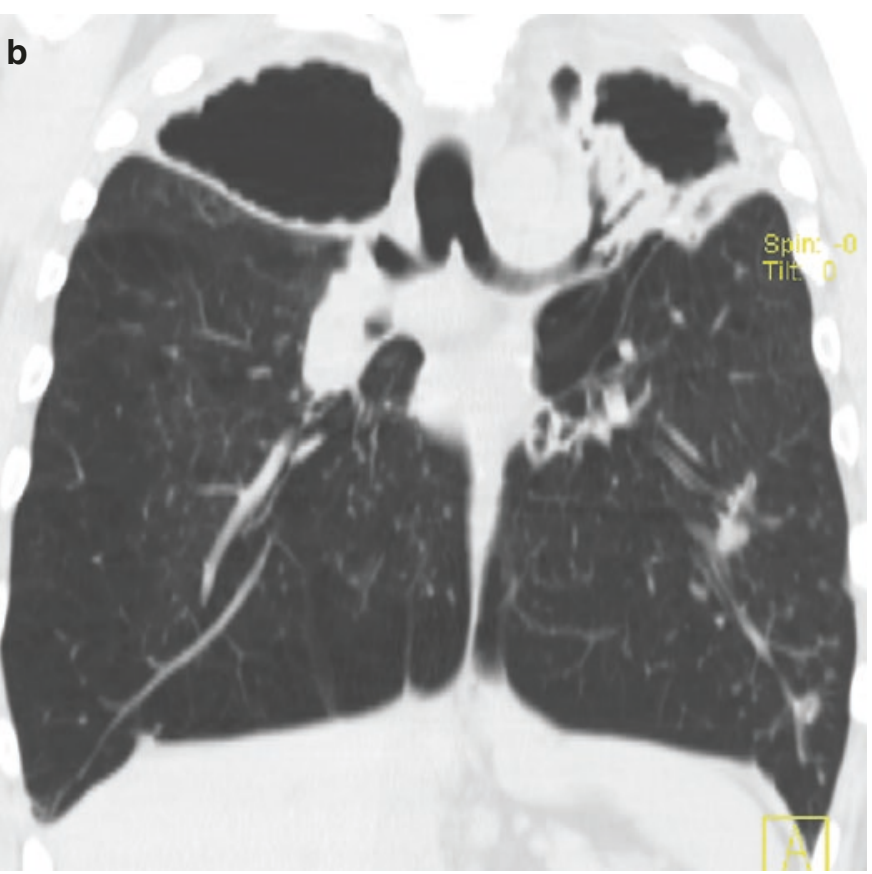

left side. (b) Coronal CT image in lung window demonstrates bilateral upper lobe cavitary lesions with scarring and atelectasis in the left lung 

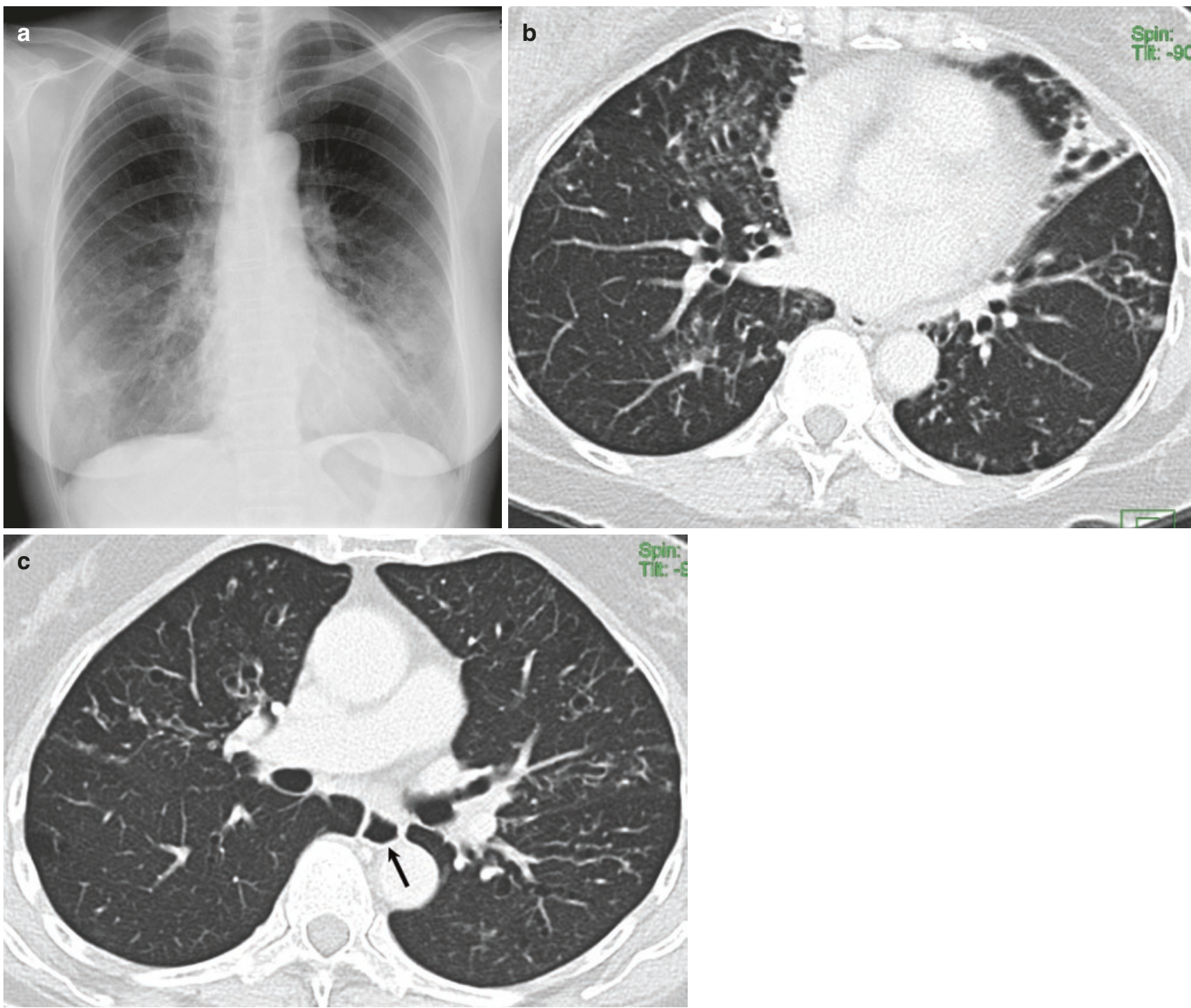

Fig. 6.13 Bronchiectatic form of atypical mycobacterial infection. (a) Frontal chest radiograph shows ill-defined opacities in the mid- and lower zones. (b, c) Axial CT images show bronchiectasis and centri- lobular nodules, predominantly in the right middle lobe and lingula. There is dilatation of the esophagus (black arrow) commonly seen in these patients
Table 6.6 Imaging features of pulmonary cryptococcosis

\begin{tabular}{|c|c|}
\hline Immunocompetent & Immunocompromised \\
\hline $\begin{array}{l}\text { - Small multiple nodules } \\
\text { (upper and midzone } \\
\text { predominance), patchy } \\
\text { consolidation }\end{array}$ & $\begin{array}{l}\text { - Nodules (may have cavitation in } \\
\text { some cases), consolidation, enlarged } \\
\text { hilar and mediastinal nodes } \\
\text { (predominant finding in AIDS), } \\
\text { pleural effusion }\end{array}$ \\
\hline
\end{tabular}

Table 6.7 Imaging features of pulmonary candida infection

\begin{tabular}{l|l}
\hline Chest radiograph & CT \\
\hline $\begin{array}{l}\text { Patchy airspace } \\
\text { opacities and/or nodules }\end{array}$ & $\begin{array}{l}\bullet \text { Ground-glass opacities, nodules, } \\
\text { patchy areas of consolidation }\end{array}$ \\
\hline
\end{tabular}

immunocompromised patients with neutropenia. Angioinvasive aspergillosis is seen in severely immunocompromised patients (graft-versus-host disease following bone marrow transplant, late stages of AIDS, long-term corticosteroids, prolonged severe neutropenia). Clinical features are not reliable and early imaging is the key to identifying the pulmonary lesions. The diagnosis is confirmed only by histopathology evaluation. Mortality rates due to invasive aspergillosis can be as high as up to $70 \%$ [30]. Chronic aspergillosis is seen in patients with background chronic lung disease or diabetes and can present in cavitary or fibrosing forms [36, 37]. 

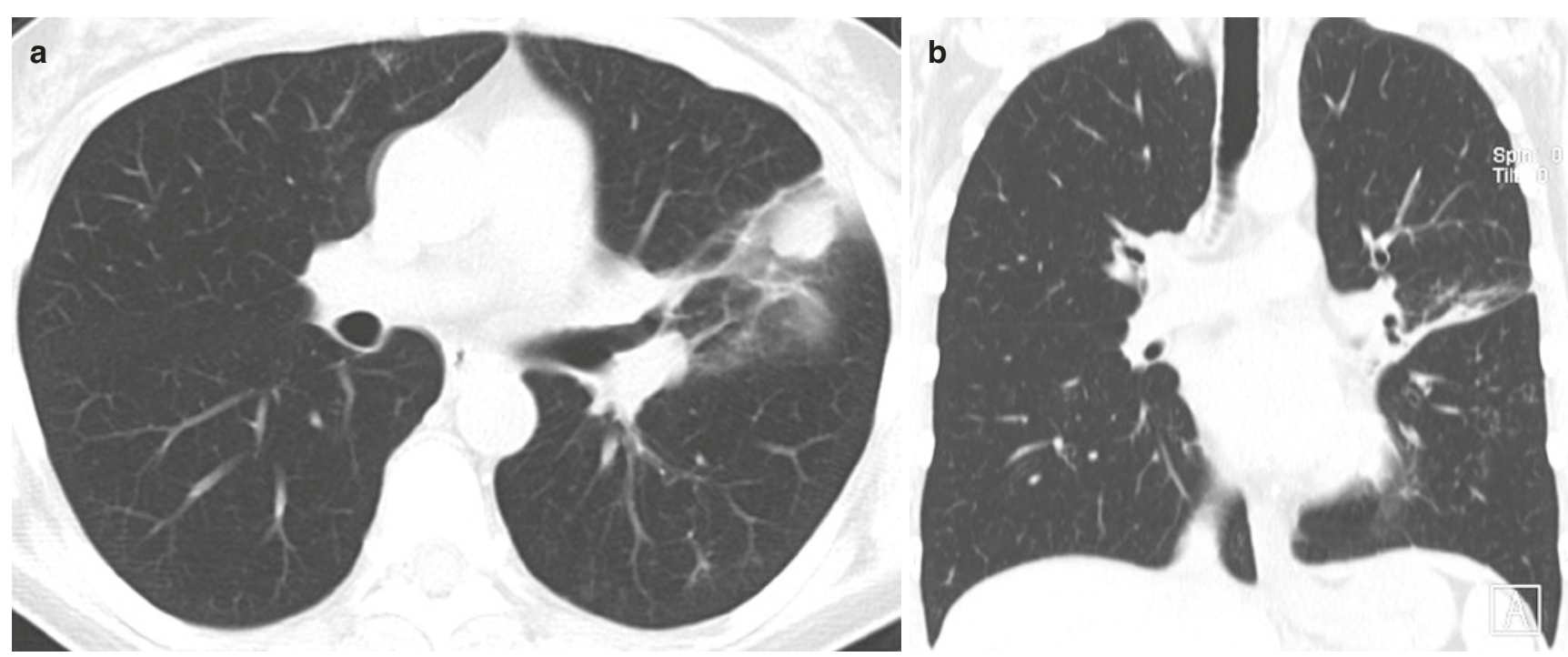

Fig. 6.14 A 59-year-old woman with coccidioidomycosis. (a, b) Axial and coronal CT images in lung window show a nodular lesion with surrounding ground-glass opacities and "tree-in-bud" opacities in the left lower lobe
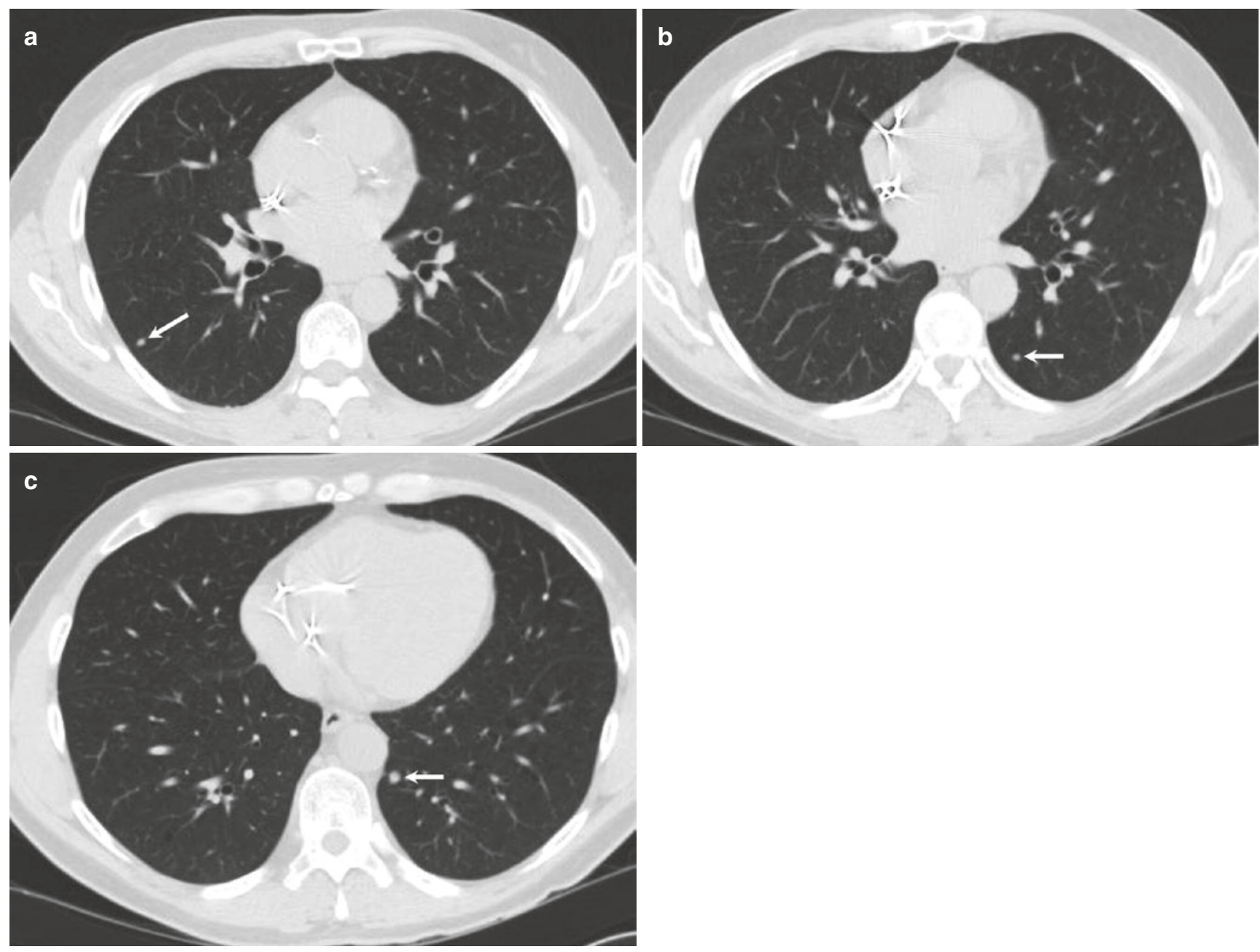

Fig. 6.15 Blastomycosis in a 55-year-old liver transplant recipient. (a-c) Axial CT images show small lung nodules (white arrows) 
Table 6.8 Synopsis of imaging findings in different forms of pulmonary aspergillosis

\begin{tabular}{|c|c|}
\hline $\begin{array}{l}\text { Aspergilloma (most common } \\
\text { form seen on imaging) }\end{array}$ & $\begin{array}{l}\text { Intracavitary usually mobile soft-tissue mass with surrounding crescent of air. Rarely, soft tissue obliterates } \\
\text { the surrounding air crescent. There may be reactive pleural thickening }\end{array}$ \\
\hline $\begin{array}{l}\text { Allergic bronchopulmonary } \\
\text { aspergillosis (ABPA) }\end{array}$ & $\begin{array}{l}\text { - Chest radiograph: } \\
\text { Consolidation, atelectasis, mucoid impaction hyperinflated lungs, tubular or ring opacities, volume loss } \\
\text { - HRCT: } \\
\text { Fleeting ground-glass opacities or consolidation } \\
\text { Bronchiectasis (central, upper lobe, cystic), mucous plugging (bronchocele formation: "finger in glove" sign), } \\
\text { areas of atelectasis, bronchial wall thickening, mosaic attenuation, areas of air trapping }\end{array}$ \\
\hline $\begin{array}{l}\text { Semi-invasive or subacute } \\
\text { invasive or chronic } \\
\text { necrotizing aspergillosis } \\
\text { (CNA) }\end{array}$ & $\begin{array}{l}- \text { Early: } \\
\text { Upper zone opacity } \\
\text { - Late: } \\
\text { Similar to aspergilloma (air crescent sign), multiple cavities, surrounding infiltrates, expanding cavity, } \\
\text { adjacent pleural thickening }\end{array}$ \\
\hline $\begin{array}{l}\text { Airway invasive or } \\
\text { bronchopneumonic } \\
\text { aspergillosis (less common } \\
\text { invasive form) }\end{array}$ & $\begin{array}{l}\text { Tracheobronchial wall thickening } \\
\text { Bronchiolitis: centrilobular nodules with "tree-in-bud" opacities } \\
\text { Bronchopneumonia (peribronchial consolidation) }\end{array}$ \\
\hline $\begin{array}{l}\text { Angioinvasive aspergillosis } \\
\text { (most aggressive form, } \\
\text { life-threatening) }\end{array}$ & $\begin{array}{l}- \text { Chest radiograph: } \\
\text { Peripheral nodules or masses } \\
\text { • CT: } \\
\text { Nodules or masses with surrounding ground-glass opacities ("halo sign"), cavitation } \\
\text { Certain cases show central ground-glass opacity with surrounding higher-density consolidation ("reverse halo" } \\
\text { sign) } \\
\text { Peripheral wedge-shaped consolidation (areas of infarction) } \\
\text { "Air crescent" sign in the recovery phase }\end{array}$ \\
\hline $\begin{array}{l}\text { Chronic pulmonary } \\
\text { aspergillosis }\end{array}$ & $\begin{array}{l}\text { - Cavitary form (more common): single or multiple lung cavities, may contain the fungal ball } \\
\text { - Fibrosing form (untreated cases): extensive scarring }\end{array}$ \\
\hline
\end{tabular}
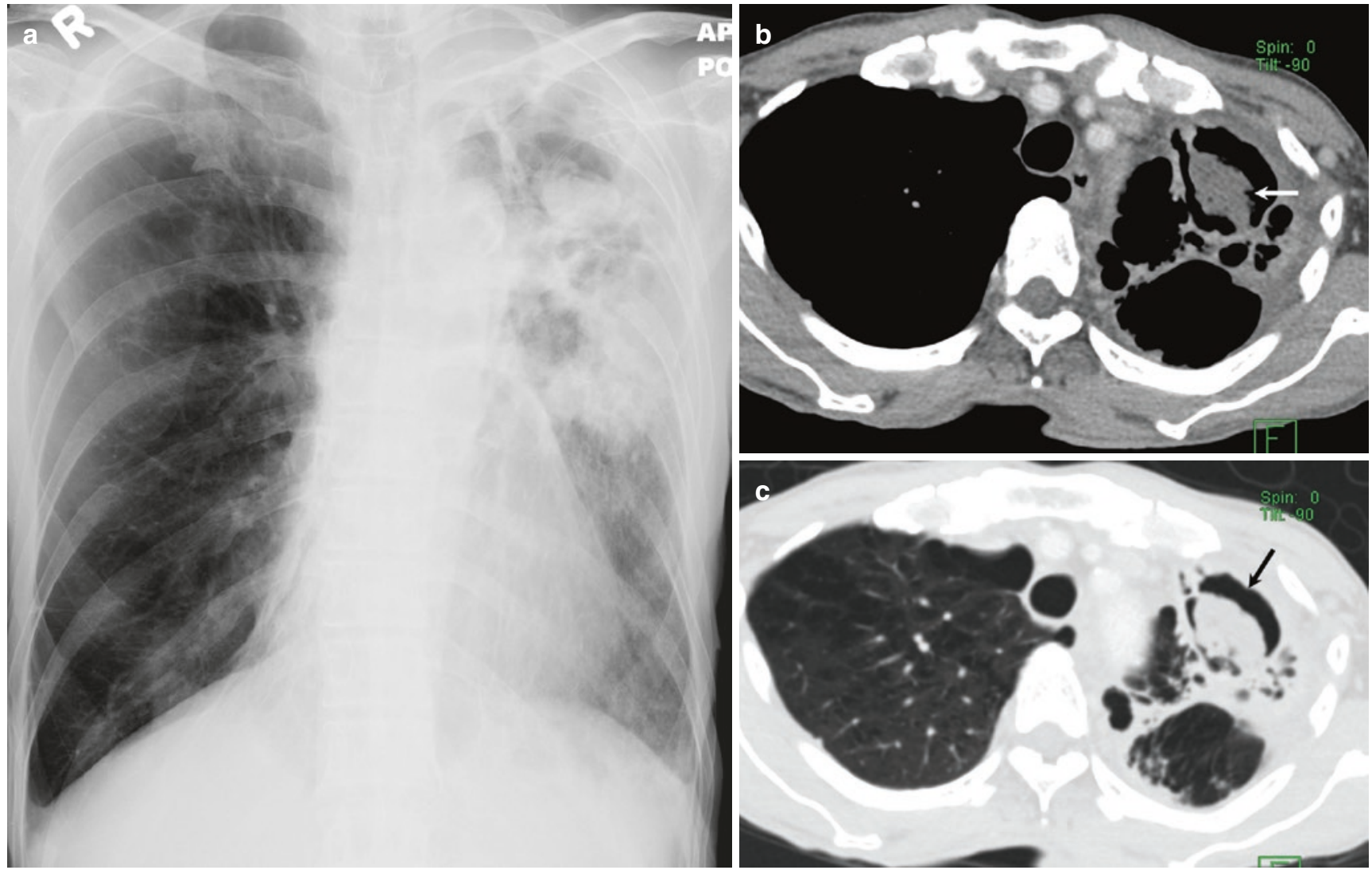

Fig. 6.16 A 69-year-old man with aspergilloma. (a) Frontal chest radiograph shows a lucent focus in the left upper zone with round opacity within, on the background of volume loss in the left hemithorax, extensive left lung opacities, and scarring. (b, c) Axial CT images show a left upper lobe cavity containing a soft-tissue density (white arrow) with surrounding air crescent (black arrow) 

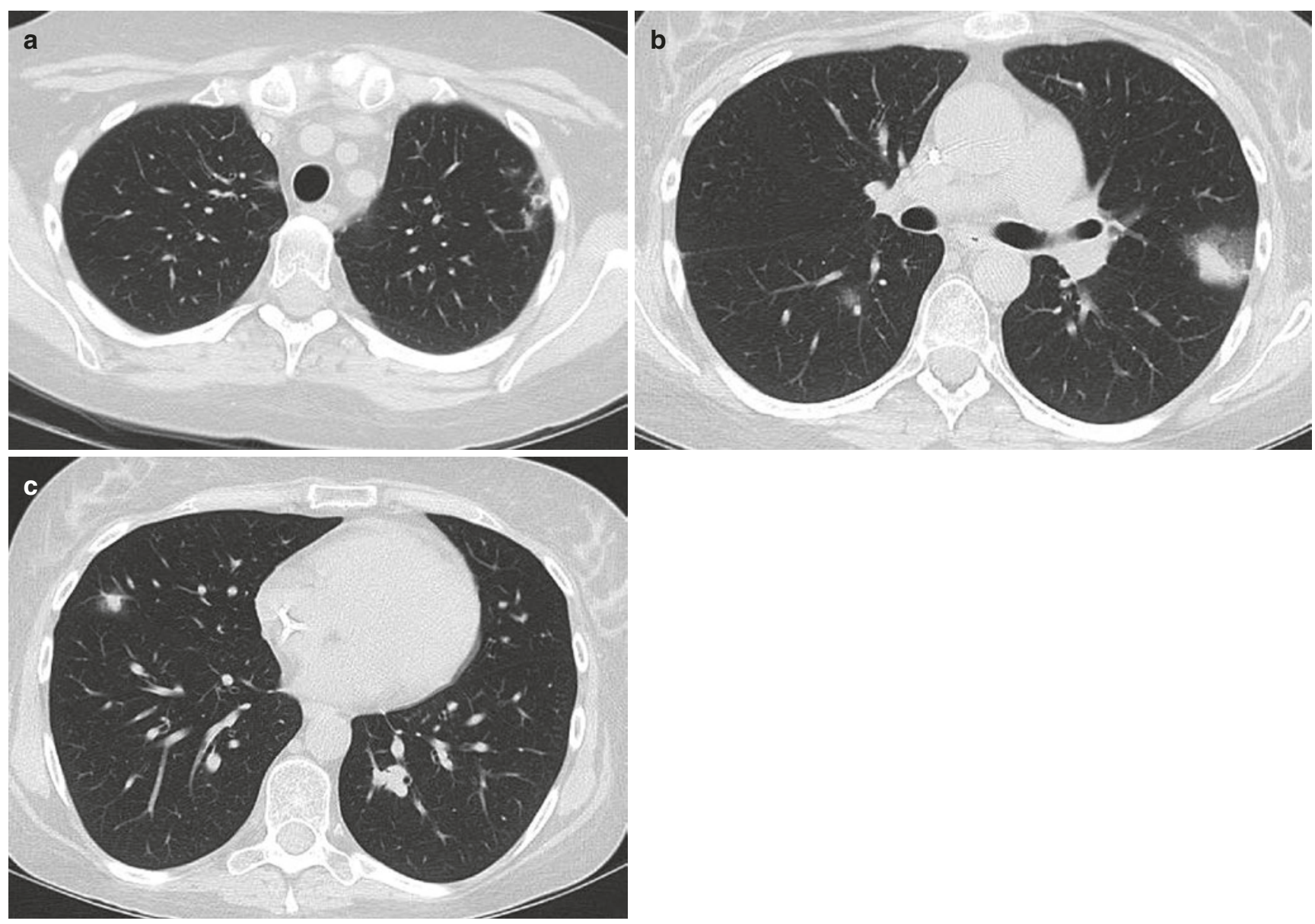

Fig. 6.17 Aspergillosis in a 28-year-old woman with acute lymphoid leukemia. (a-c) HRCT images show lung nodules with surrounding groundglass attenuation and cavitation

\subsubsection{Histoplasmosis}

Histoplasmosis is caused by Histoplasma capsulatum, typically resulting in granulomatous inflammation, necrosis, and fibrosis, thereby resembling tuberculosis [30]. Acute histoplasmosis is often difficult to identify on chest radiograph, and CT evaluation is needed to identify the abnormalities. In some cases, the infection can extend to the mediastinal structures, resulting in fibrosing mediastinitis. Chronic histoplasmosis is a rare disease, typically seen in patients with background chronic obstructive pulmonary disease. Imaging findings in chronic histoplasmosis include patchy consolidation (upper lobe predominance), upper lobe cavitation, calcified hilar and mediastinal nodes, and rarely broncholithiasis (Table 6.9).

\subsubsection{Nocardiosis}

Nocardiosis is mostly commonly caused by Nocardia asteroides or Nocardia brasiliensis and can result in pulmonary or systemic infection. Nocardia asteroides is usually responsible for the pulmonary disease, causing severe opportunistic infection in immunocompromised patients with non-specific imaging findings (Fig. 6.20) (Table. 6.10).

\subsubsection{Pneumocystis jiroveci Infection}

Pneumocystis jiroveci pneumonia is caused by a yeastlike organism and was previously known as Pneumocystis carinii [38]. The infection is seen in AIDS (CD4 counts of below 100 cells $/ \mathrm{mm}^{3}$ ), patients with hematological cancers, solid organ transplant recipients, and bone marrow transplant patients. Dyspnea and nonproductive cough are the usual presenting symptoms. The typical radiological features are listed in Table 6.11 (Figs. 6.21, 6.22, and 6.23). Atypical imaging features can be seen in patients on prophylactic treatment. These features include consolidation, small nodules with tree-in-bud opacities, cavitating nodules, enlarged lymph nodes, and pleural effusion. Diagnosis is confirmed by identifying the organisms in bronchoalveolar lavage, in sputum, or by monoclonal antibody testing. Gallium-67 lung scintigraphy test has 

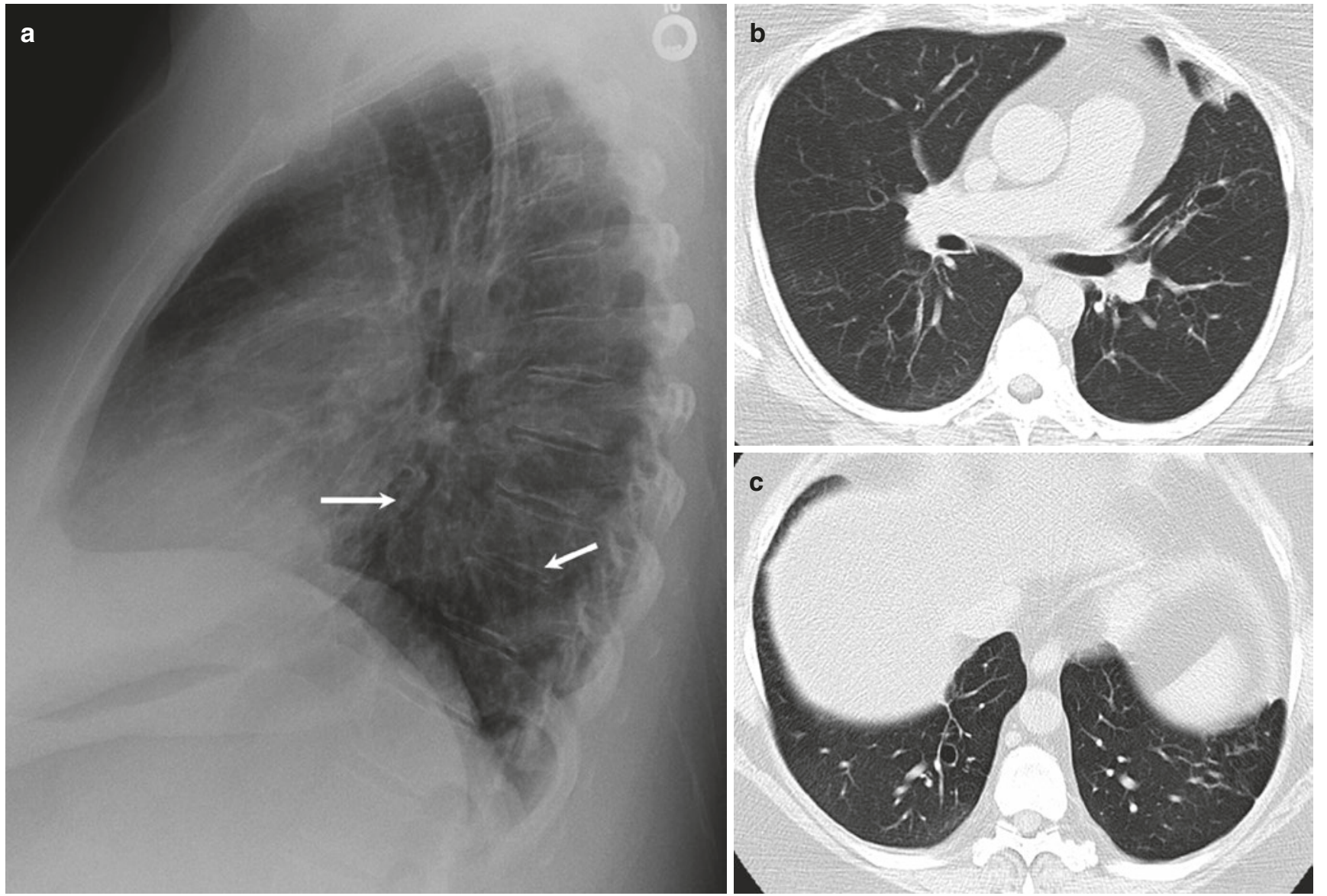

Fig. 6.18 Allergic bronchopulmonary aspergillosis (ABPA) in a 37-year-old woman with long-standing steroid-dependent asthma. (a)

thickening, and bronchiectasis (white arrow). (b, c) HRCT images Lateral chest radiograph shows reduced lung volume, bronchial wall show areas of atelectasis, central cystic bronchiectasis, and bronchial wall thickening
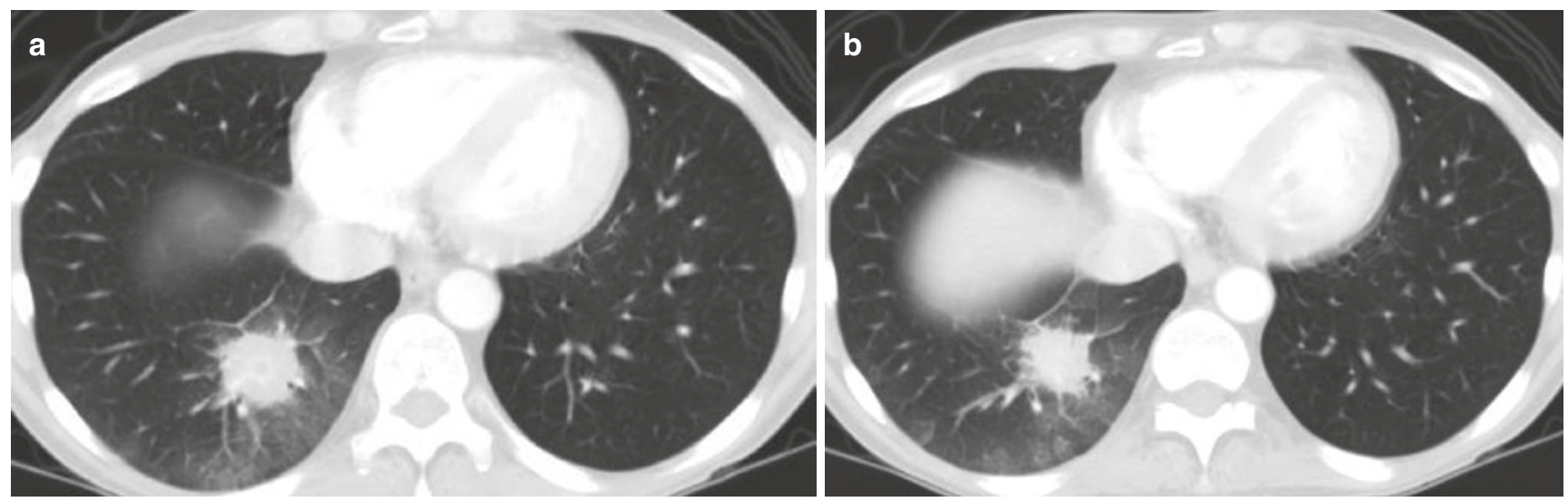

Fig. 6.19 Angioinvasive aspergillosis in a 42-year-old man presenting with neutropenic fever following chemotherapy for acute myeloid leukemia. (a, b) Axial CT images show right lower lobe nodule with "halo" sign 
been shown to be highly sensitive for PCJ infection, and a negative test result virtually excludes this infection.

Table 6.9 Imaging features of pulmonary histoplasmosis

Chest radiograph

- Ill-defined opacities, solitary nodule with calcification (healing stage)

\section{CT findings}

- Patchy consolidation or solitary nodule with central or diffuse calcification

- Disseminated disease in immunocompromised: reticulonodular or miliary opacities, enlarged mediastinal, hilar nodes, changes of fibrosing mediastinitis

\subsubsection{Viral Infections}

Various RNA and DNA viruses can cause clinically important pulmonary infections, in both immunocompetent and immunocompromised hosts. Clinical presentations of most of these infections are similar, and the diagnosis is heavily reliant on the background picture, risk factors, and exposures [7]. Imaging is useful in identifying the pattern and extent of the disease, assessing response on follow-up and for diagnostic procedures. Chest radiographs are unremarkable or may demonstrate non-specific changes, like patchy ground-glass opacities, consolidations, effusion, or nod-
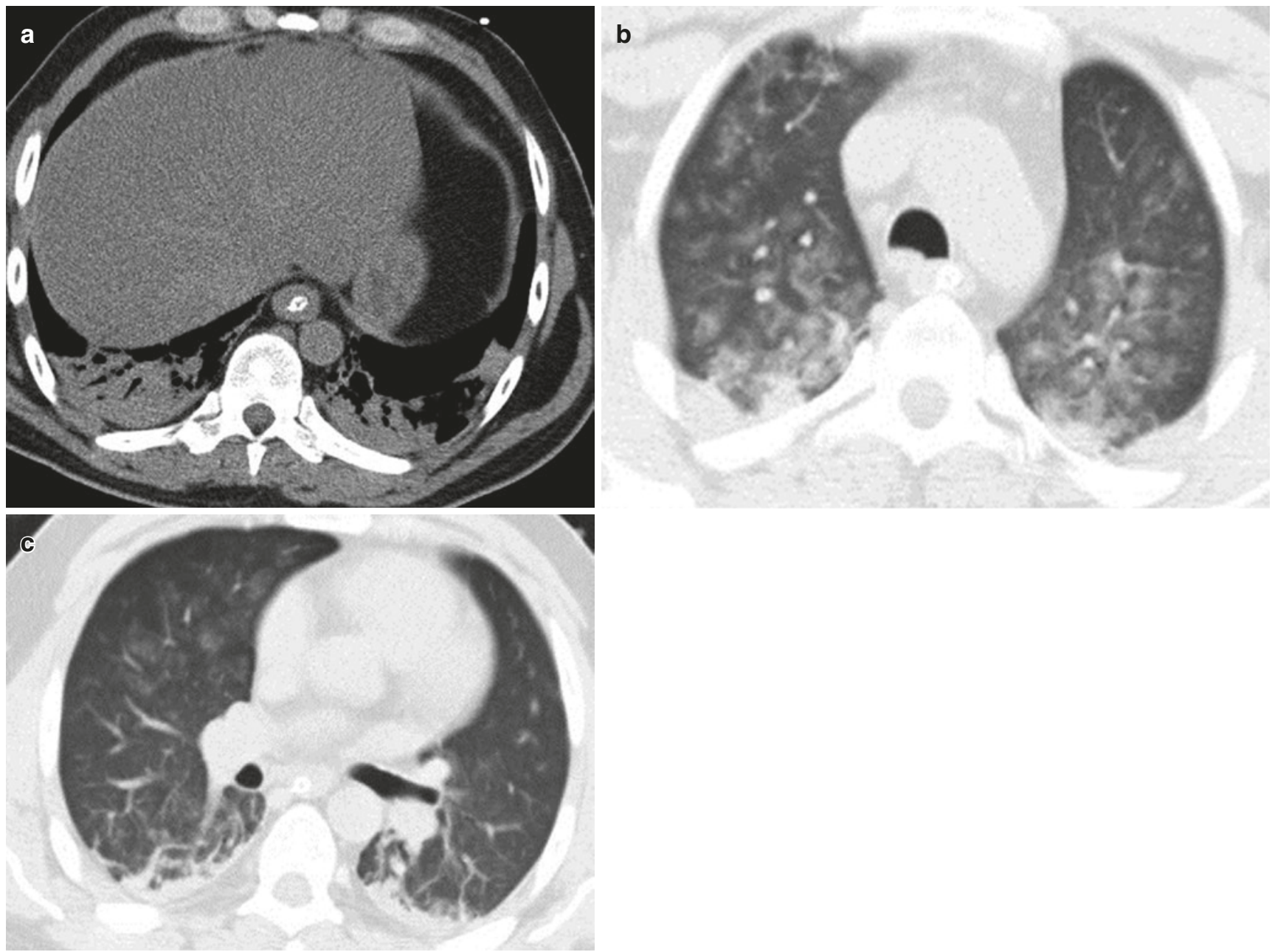

Fig. 6.20 Nocardiosis in a 58-year-old man. (a) CT thorax axial image shows lower lobe consolidation. Axial CT images (b, c) show multiple ground-glass density nodules 
ules. Although imaging features in bacterial and viral pulmonary infections show considerable overlap, CT may be useful by demonstrating few main patterns of disease (Table 6.12) [39]. Some viral infections are more common

Table 6.10 Imaging features of pulmonary nocardiosis

\begin{tabular}{l|l}
\hline Chest radiograph & CT findings \\
\hline • Lobar & $\bullet$ Consolidation with areas of abscess formation, \\
consolidation & cavitation, solitary nodules, or mass \\
\cline { 2 - 2 } & $\begin{array}{l}\bullet \text { Pleural thickening, effusion, empyema } \\
\text { necessitans }\end{array}$ \\
\hline $\begin{array}{l}\text { - Pleural } \\
\text { effusion }\end{array}$ & $\begin{array}{l}\text { Disseminated disease in immunocompromised: } \\
\text { multiple nodules and areas of cavitation }\end{array}$ \\
\hline
\end{tabular}

Table 6.11 Imaging features of PCJ infection

\begin{tabular}{|c|c|}
\hline Chest radiograph & CT findings \\
\hline - Usually non-specific & $\begin{array}{l}\text { - Perihilar and midzone ground-glass } \\
\text { opacities, peripheral sparing }\end{array}$ \\
\hline $\begin{array}{l}\text { - Fine reticular opacities } \\
\text { which can progress to } \\
\text { ground-glass opacities or } \\
\text { consolidation }\end{array}$ & $\begin{array}{l}\text { - "Crazy-paving pattern" with an } \\
\text { overlap of reticular opacities and } \\
\text { septal thickening, sometimes miliary } \\
\text { pattern with small nodules }\end{array}$ \\
\hline $\begin{array}{l}\text { - Perihilar distribution, } \\
\text { pneumatoceles }\end{array}$ & $\begin{array}{l}\text { - Pneumatoceles in about one-third } \\
\text { cases (improve after the acute stage). } \\
\text { Upper zone predominance on patients } \\
\text { on prophylactic aerosols increases the } \\
\text { risk of pneumothorax }\end{array}$ \\
\hline $\begin{array}{l}\text { - Usually no effusion or } \\
\text { lymphadenopathy }\end{array}$ & $\begin{array}{l}\text { - Usually no effusion or } \\
\text { lymphadenopathy }\end{array}$ \\
\hline
\end{tabular}
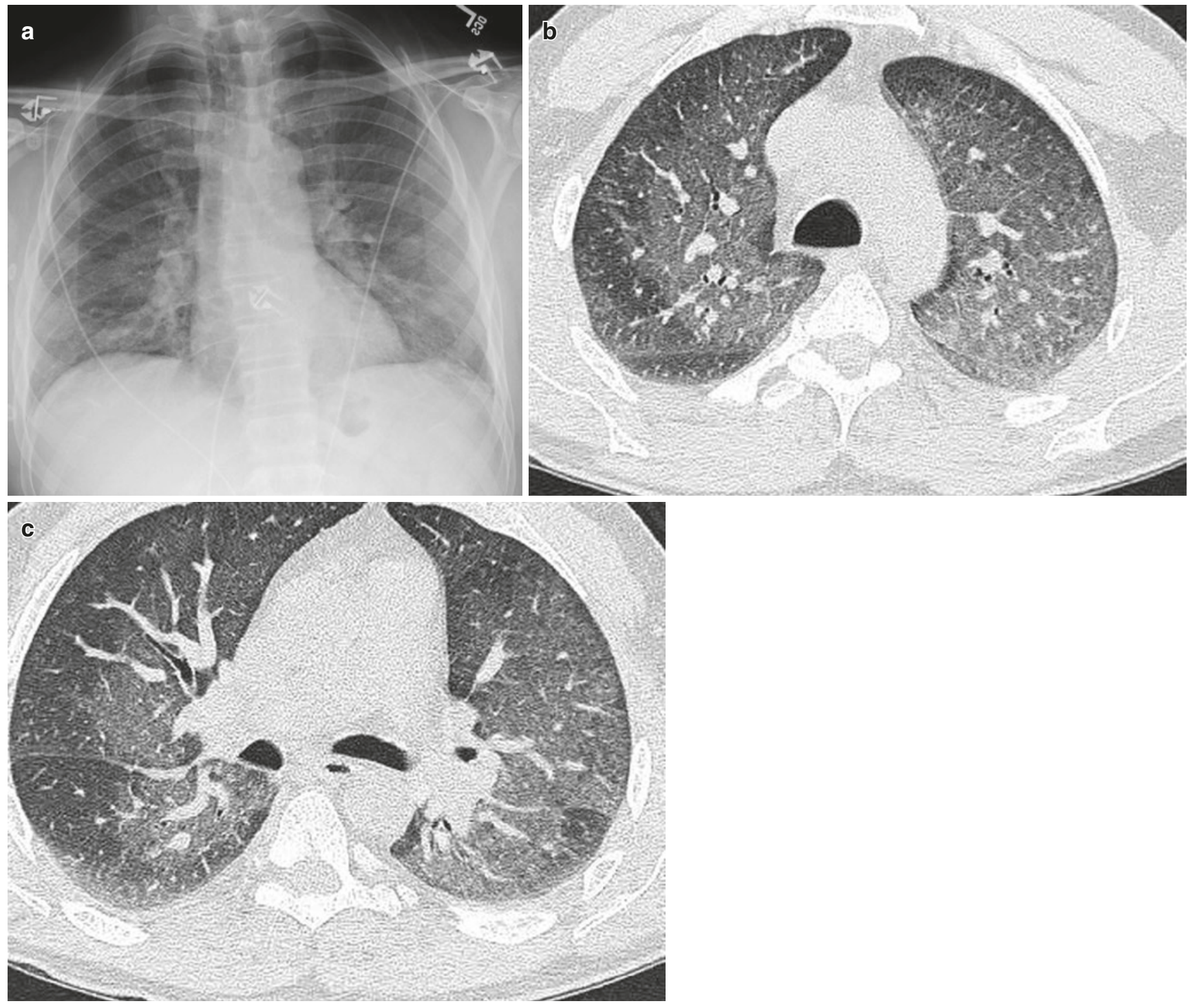

Fig. 6.21 PCJ infection in an immunocompromised male patient. (a) Frontal chest radiograph shows subtle diffuse haziness. (b, c) Axial CT images in lung window show extensive ground-glass pattern densities with midzone and hilar predominance. There is no pleural effusion or lymphadenopathy 


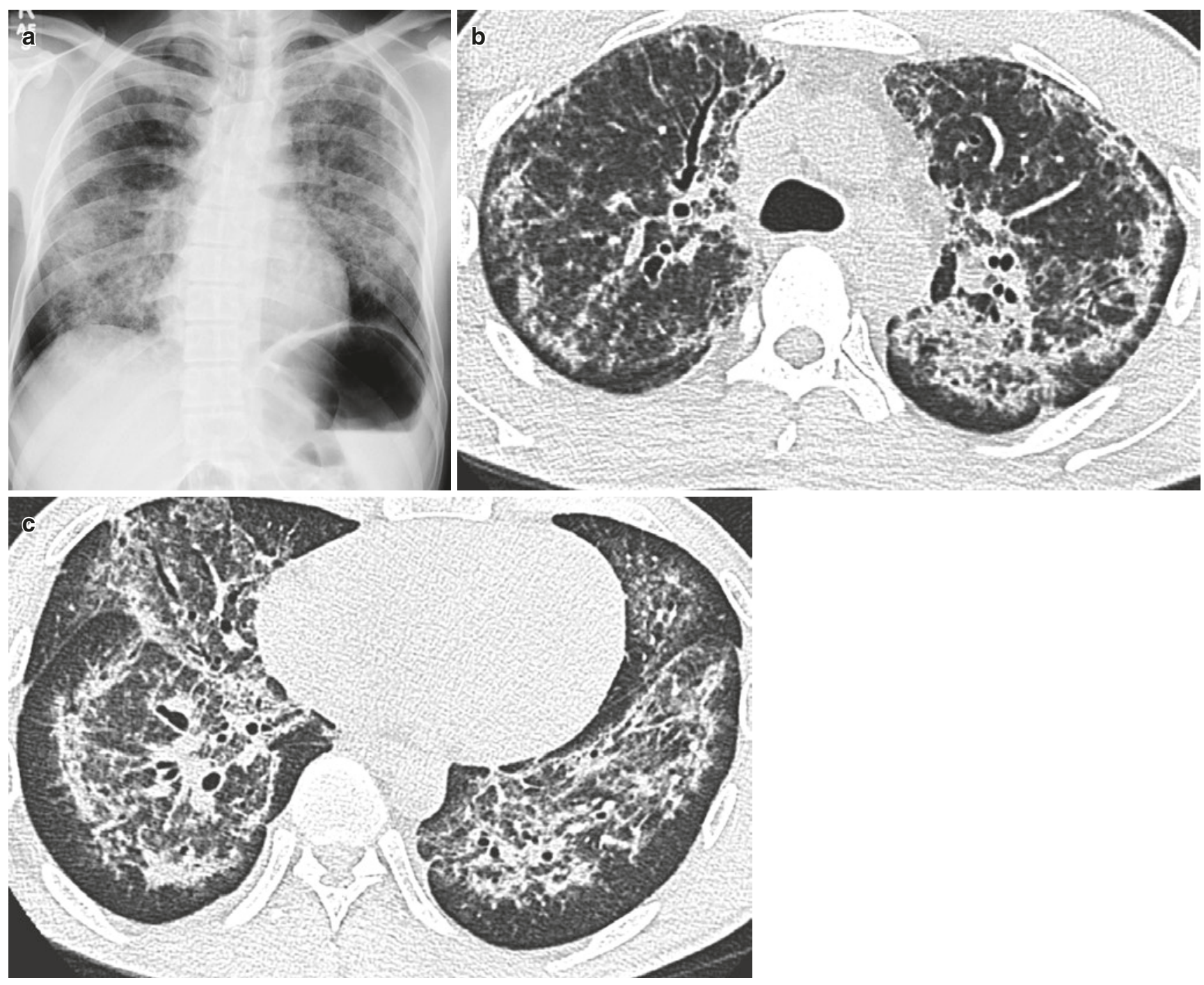

Fig. 6.22 PCJ infection with striking subpleural sparing. (a) Frontal chest radiograph shows extensive bilateral reticular opacities and ground-glass opacities. (b, c) Axial HRCT images show marked septal thickening, ground-glass changes, and peribronchial involvement sparing the subpleural lung. There is no pleural effusion or mediastinal lymphadenopathy in specific scenarios with a particular imaging pattern. Ground-glass opacities, multiple nodules, or "interstitial pneumonia" pattern in a patient with hematopoietic stem cell transplant is most commonly seen in cytomegalovirus infection.

\subsubsection{Aspiration Pneumonia}

Aspiration pneumonia results from the passage of material from the oropharynx in the tracheobronchial tree instead of esophagus. Central nervous system diseases, drug overdose, alcohol intoxication, esophageal motility disorders, and anesthesia are some common predisposing risk factors for aspiration pneumonia [40]. It can be classified as acute and chronic aspiration pneumonitis, based on the time course. Mendelson syndrome is a form of acute chemical pneumonitis due to aspiration of acidic gastric content during general anesthesia usually for obstetric procedures. Imaging features are similar to noncardiogenic pulmonary edema. When aspiration occurs in a recumbent patient, the changes are seen involving the posterior segment of the upper lobes and the superior segment or posterior basal segments of lower lobes (Figs. 6.1, 6.24, 6.25, 6.26, and 6.27) (Table 6.13). Bilateral 

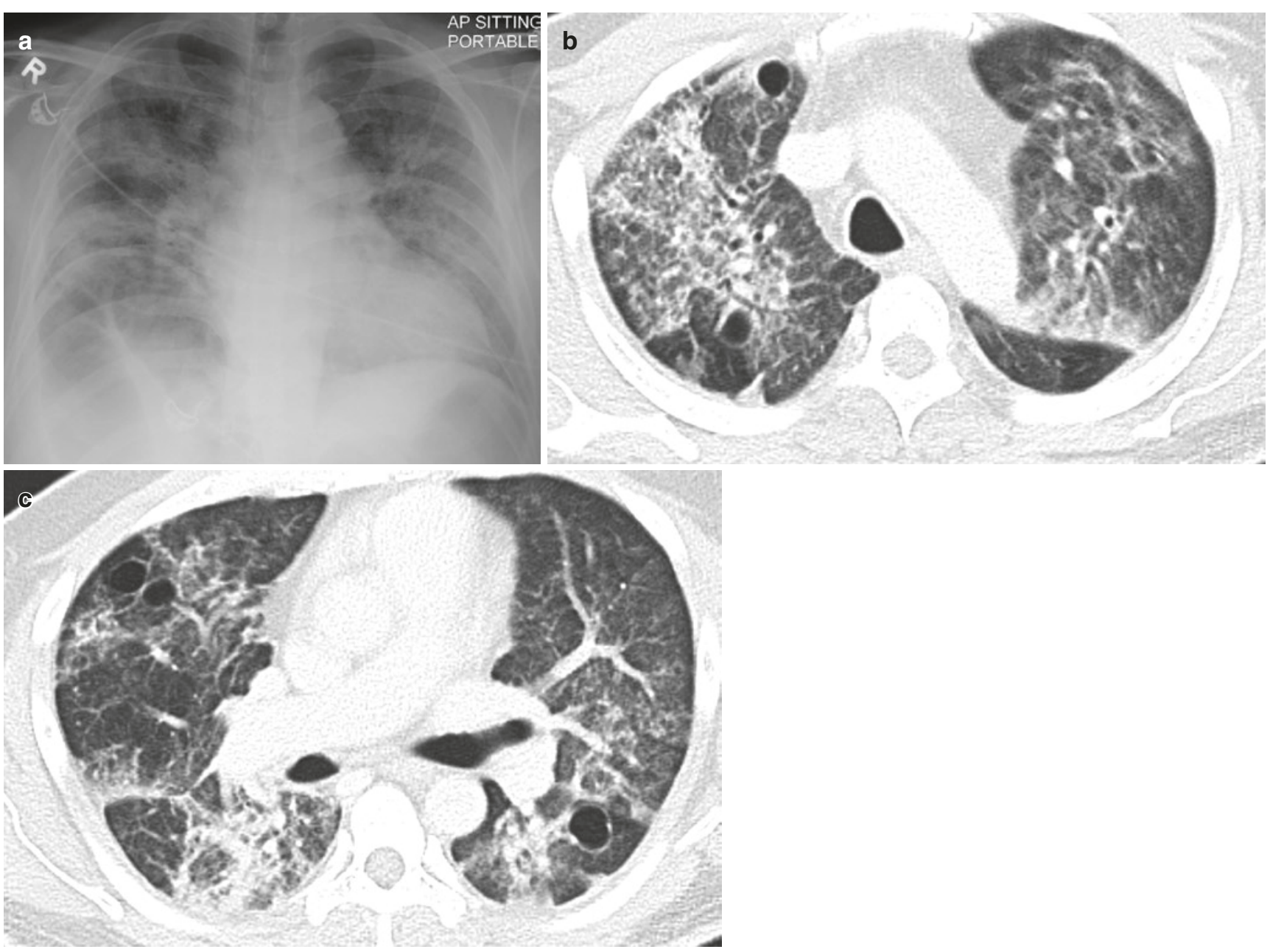

Fig. 6.23 PCJ infection with pneumatoceles. (a) Frontal chest radiograph shows bilateral lung opacities, predominantly in midzones. (b, c) Axial CT images in lung window show bilateral marked septal thickening, ground-glass pattern opacification, and thin-walled cysts

Table 6.12 CT findings in viral pulmonary infections

\begin{tabular}{l|l}
\hline Cause & Predominant pattern \\
\hline RNA viruses & $\begin{array}{l}\text { Ground-glass opacities, consolidation, nodules, tree-in-bud opacities } \\
\text { Hantavirus infection: interlobular septal thickening, acute respiratory distress syndrome } \\
\text { Coronavirus infection: crazy-paving pattern }\end{array}$ \\
\hline RSV & $\begin{array}{l}\text { Airway-centric pattern with tree-in-bud opacities, prominent bronchial/bronchiolar wall thickening, and surrounding } \\
\text { consolidation }\end{array}$ \\
\hline Adenovirus & Multifocal ground-glass opacities, consolidation, bronchial wall thickening \\
\hline Varicella & Ground-glass opacities, consolidation, nodules with a surrounding halo \\
\hline CMV & Nodules with calcification or surrounding halo, ground-glass opacities, consolidation \\
\hline & Ground-glass opacities, consolidation, nodules with a surrounding halo
\end{tabular}

basal, lingula, and middle lobe involvement can be seen in otherwise ambulatory patients. Chronic/recurrent aspiration pneumonitis usually appears as small and large airways disease but may mimic fibrotic lung disease or even a lung mass. Lung abscess or empyema can be seen in complicated cases. 

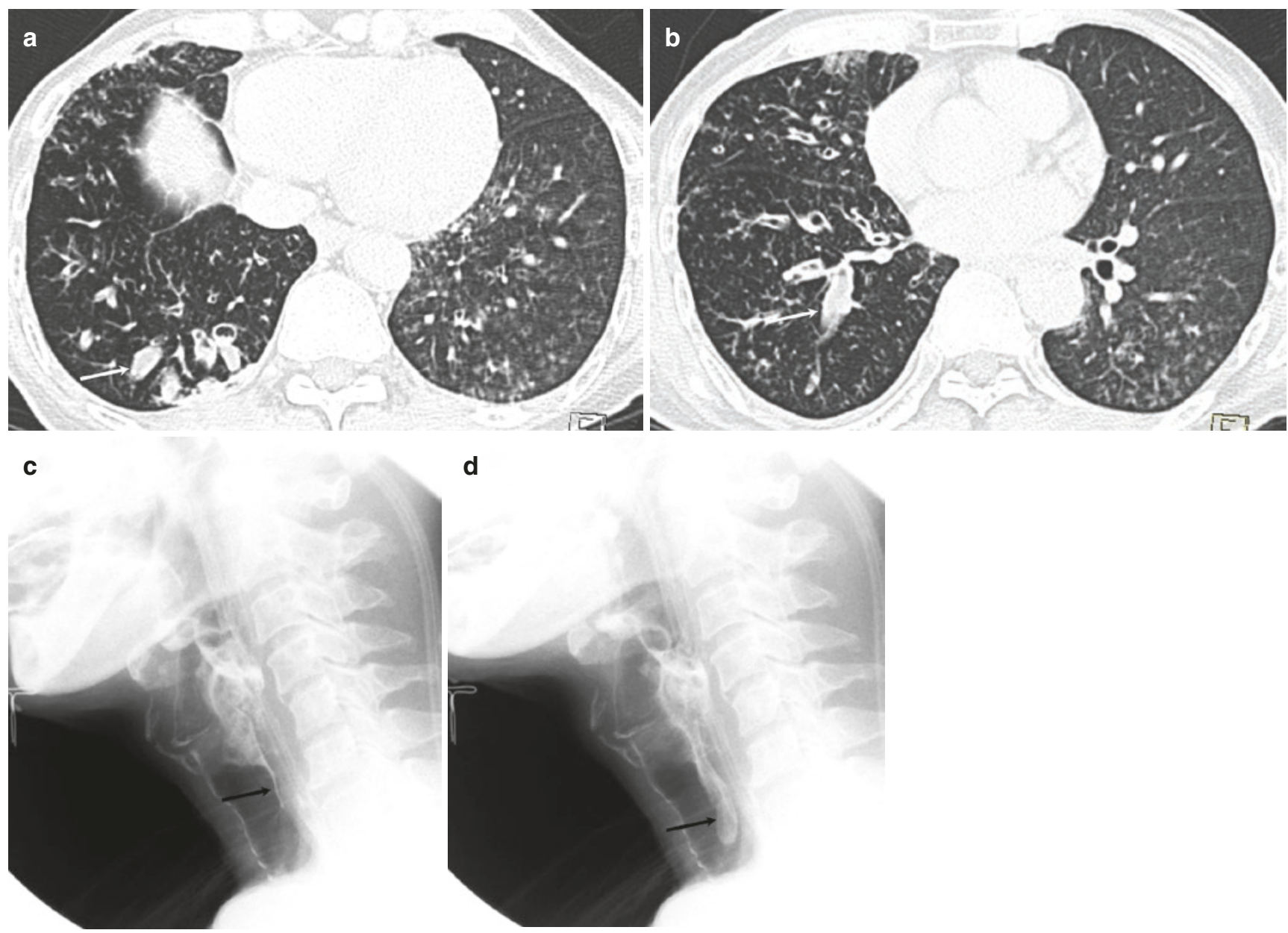

Fig. 6.24 A 76-year-old man with stroke and recurrent aspiration. (a, b) Axial CT images show bronchiectasis in bilateral lower lobes with sive tree-in-bud opacities. (c, d) Serial video fluoroscopy images show mucus plugging (arrow), marked bronchial wall thickening, and exten-

\section{aspiration of thin barium (arrow)}
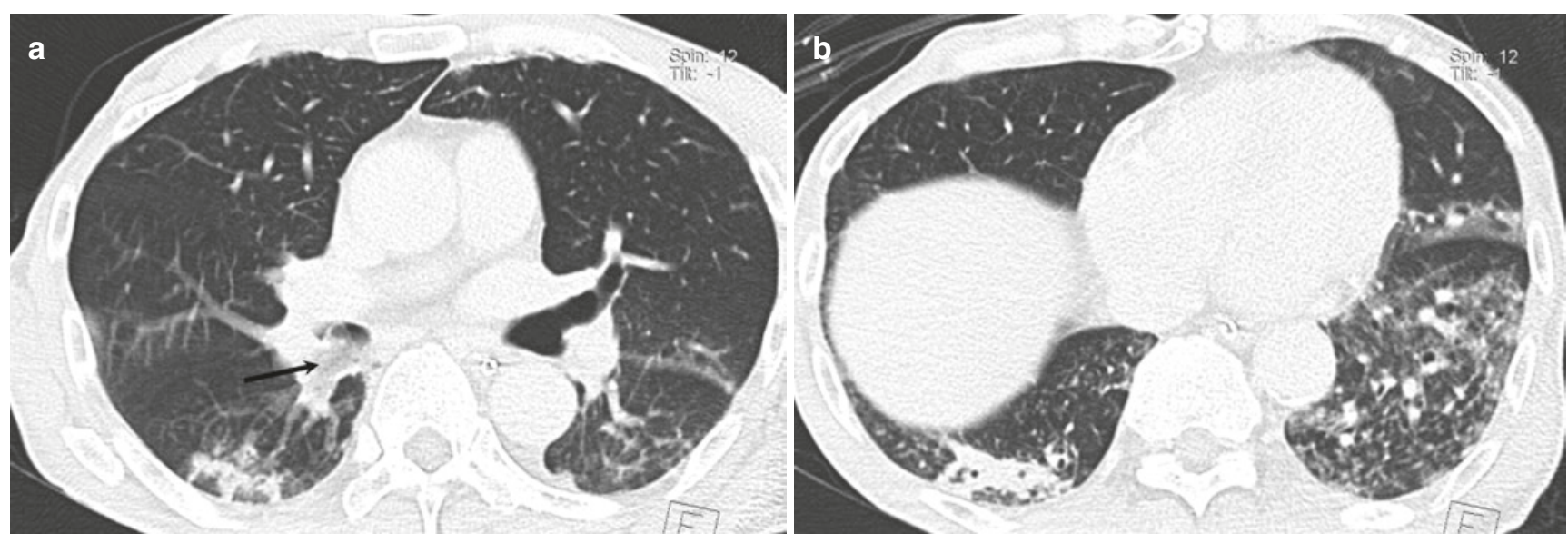

Fig. 6.25 Recurrent aspiration. (a, b) Axial CT images show consolidative opacity in the right posterior lung base, bronchiectasis, and tree-in-bud opacities in the left lung base. Note bubbly fluid in the right lower lobe bronchus (arrow) 


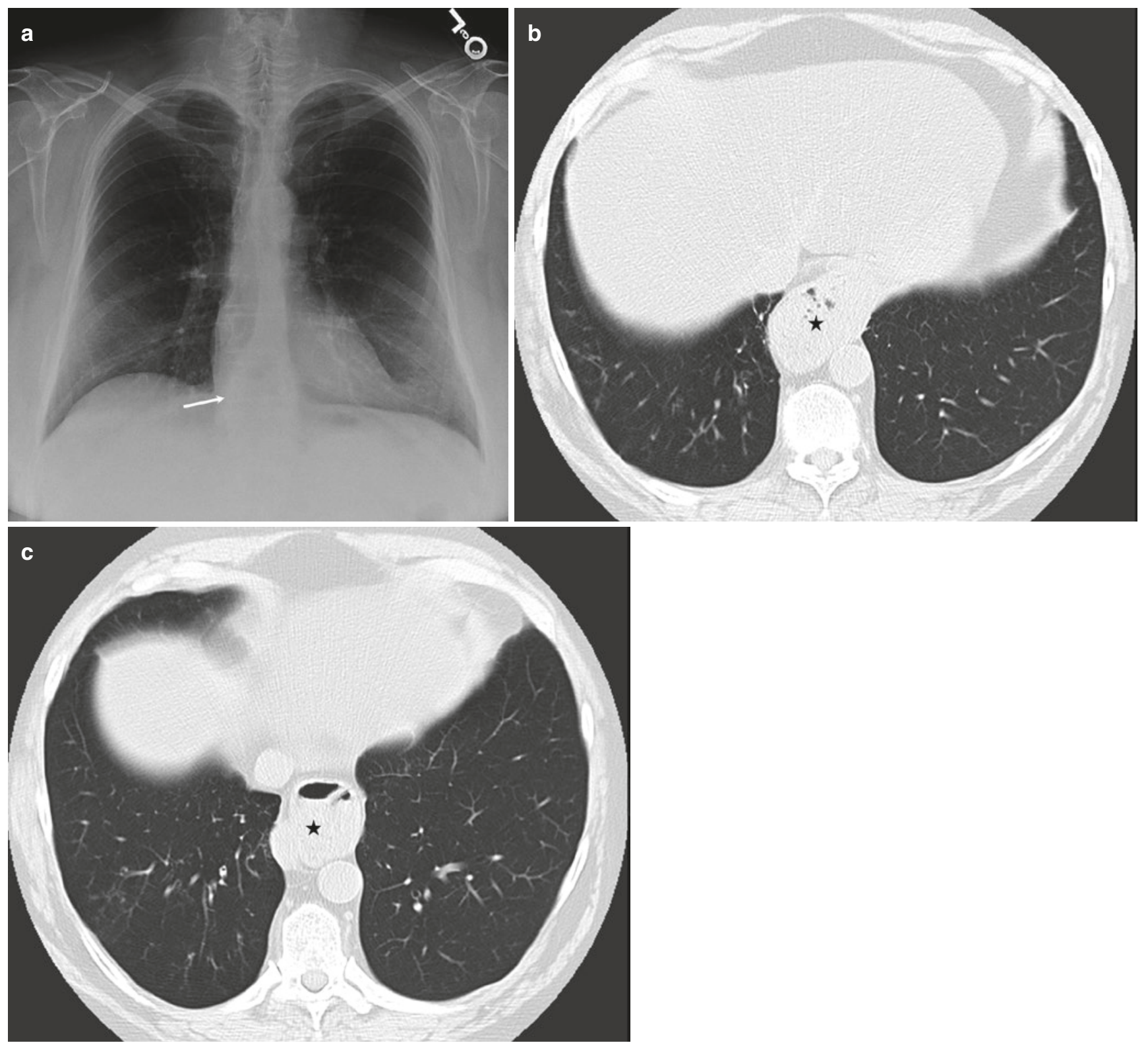

Fig. 6.26 Mild changes of recurrent aspiration. (a) Frontal chest radiograph shows a retrocardiac opacity displacing the azygo-esophageal recess (arrow). (b, c) Axial CT images show moderate size hiatal hernia (asterisk) with subtle ground-glass opacities, bronchial wall thickening, and bronchial dilatation in the right lower lobe 

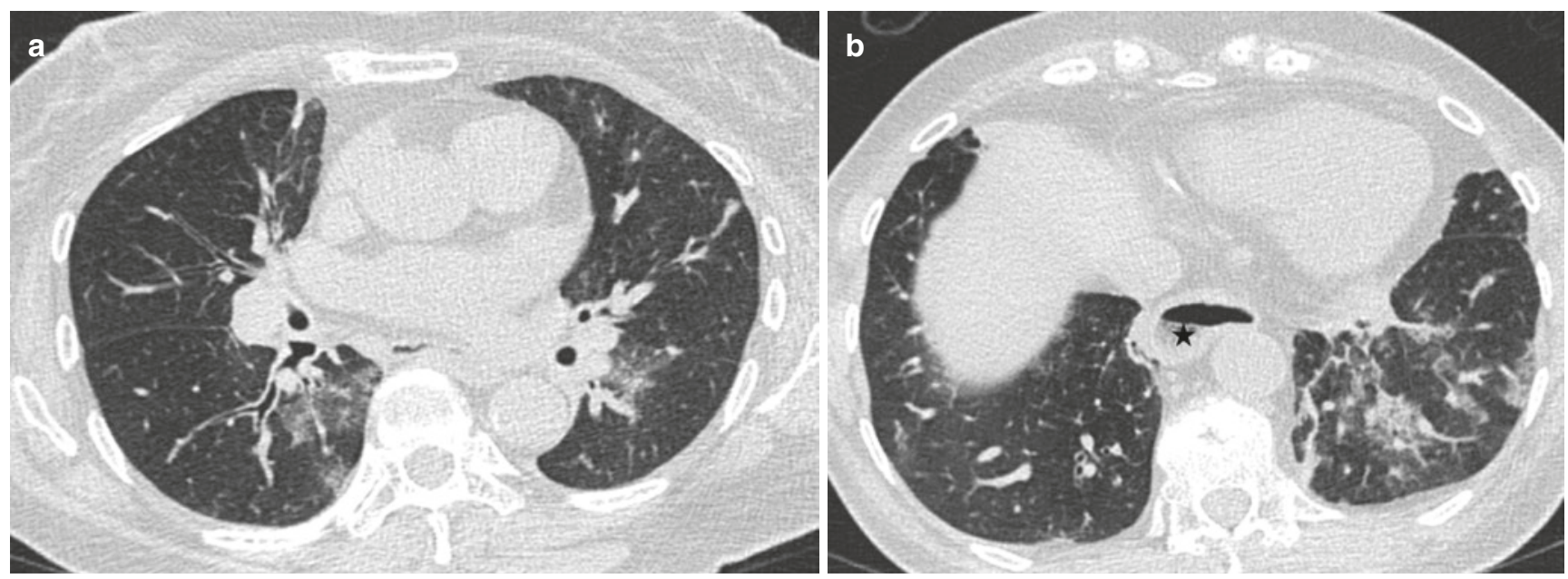

Fig. 6.27 Aspiration changes in a patient with scleroderma. (a, b) Axial CT images show dilated esophagus with air-fluid level (asterisk) with bilateral peribronchial ground-glass opacities. The opacities

Table 6.13 Imaging findings in aspiration pneumonitis

\begin{tabular}{l|l}
\hline Chest radiograph & CT findings \\
\hline $\begin{array}{l}\text { - Dilated esophagus } \\
\text { or hiatal hernia }\end{array}$ & - Abnormal esophagus \\
\hline $\begin{array}{l}\text { - Lobar } \\
\text { consolidation, if } \\
\text { there is associated } \\
\text { infection }\end{array}$ & $\begin{array}{l}\text {-Aspirated material can be identified within } \\
\text { the tracheobronchial tree }\end{array}$ \\
\hline $\begin{array}{l}\text { - Migratory } \\
\text { opacities in } \\
\text { recurrent aspiration }\end{array}$ & $\begin{array}{l}\text { - Various patterns (bronchopneumonia, lobar } \\
\text { pneumonia, bronchiolitis) involving } \\
\text { posterior segment of upper lobes or superior } \\
\text { and basal segment of lower lobes } \\
\text { - Bronchiectasis with associated small } \\
\text { airways disease in lower lungs (recurrent } \\
\text { aspiration) }\end{array}$ \\
\hline
\end{tabular}

\section{References}

1. Beigelman-Aubry C, Godet C, Caumes E. Lung infections: the radiologist's perspective. Diagn Interv Imaging. 2012;93(6):431-40.

2. Walker CM, Abbott GF, Greene RE, Shepard JA, Vummidi D, Digumarthy SR. Imaging pulmonary infection: classic signs and patterns. Am J Roentgenol. 2014;202(3):479-92.

3. Okada F, Ono A, Ando Y, Nakayama T, Ishii R, Sato H, et al. Thinsection CT findings in Pseudomonas aeruginosa pulmonary infection. Br J Radiol. 2012;85(1020):1533-8.

4. Wagner AL, Szabunio M, Hazlett KS, Wagner SG. Radiologic manifestations of round pneumonia in adults. Am J Roentgenol. 1998;170(3):723-6.

5. Worsley DF, Nambu A, Ozawa K, Kobayashi N, Tago M. Imaging of community-acquired pneumonia: roles of imaging examinations, imaging diagnosis of specific pathogens and discrimination from noninfectious diseases. World J Radiol. 2014;6(10):779-93.

6. Elliott Ferguson EC, Berkowitz EA. Lung CT: part 2, The interstitial pneumonias - clinical, histologic, and CT manifestations. Am J Roentgenol. 2012;199(4):W464-76. resolved on follow-up CT (not shown) excluding interstitial lung disease related to scleroderma

7. Franquet T. Imaging of pulmonary viral pneumonia. Radiology. 2011;260(1):18-39.

8. Lee KS, Kim TS, Han J, Hwang JH, Yoon JH, Kim Y, Yoo SY. Diffuse micronodular lung disease: HRCT and pathologic findings. J Comput Assist Tomogr. 1999;23(1):99-106.

9. Oh YW, Effmann EL, Godwin JD. Pulmonary infections in immunocompromised hosts: the importance of correlating the conventional radiologic appearance with the clinical setting. Radiology. 2000;217(3):647-56.

10. Ye R, Zhao L, Wang C, Wu X, Yan H. Clinical characteristics of septic pulmonary embolism in adults: a systematic review. Respir Med. 2014;108(1):1-8.

11. Dodd JD, Souza CA, Müller NL. High-resolution MDCT of pulmonary septic embolism: evaluation of the feeding vessel sign. Am J Roentgenol. 2006;187(3):623-9.

12. Franquet T, Müller NL, Giménez A, Martínez S, Madrid M, Domingo P. Infectious pulmonary nodules in immunocompromised patients: usefulness of computed tomography in predicting their etiology. J Comput Assist Tomogr. 2003;27(4):461-8.

13. Raju S, Ghosh S, Mehta AC. Chest CT signs in pulmonary disease: a pictorial review. Chest. 2017;151(6):1356-74.

14. Althoff Souza C, Müller NL, Marchiori E, Escuissato DL, Franquet T. Pulmonary invasive aspergillosis and candidiasis in immunocompromised patients: a comparative study of the high-resolution CT findings. J Thorac Imaging. 2006;21(3):184-9.

15. Cardinale L, Parlatano D, Boccuzzi F, Onoscuri M, Volpicelli G, Veltri A. The imaging spectrum of pulmonary tuberculosis. Acta Radiol. 2015;56(5):557-64.

16. Pombo F, Rodríguez E, Mato J, Pérez-Fontán J, Rivera E, Valvuena L. Patterns of contrast enhancement of tuberculous lymph nodes demonstrated by computed tomography. Clin Radiol. 1992;46(1):13-7.

17. Mathur M, Badhan RK, Kumari S, Kaur N, Gupta S. Radiological manifestations of pulmonary tuberculosis - a comparative study between immunocompromised and immunocompetent patients. J Clin Diagn Res. 2017;11(9):TC06-9.

18. Andreu J, Cáceres J, Pallisa E, Martinez-Rodriguez M. Radiological manifestations of pulmonary tuberculosis. Eur J Radiol. 2004;51(2):139-49. 
19. Murata K, Itoh H, Todo G, Kanaoka M, Noma S, Itoh T, et al. Centrilobular lesions of the lung: demonstration by high-resolution CT and pathologic correlation. Radiology. 1986;161(3):641-5.

20. Ofori A, Steinmetz AR, Akaasi J, Asafu Adjaye Frimpong GA Norman BR, Obeng-Baah J, Bedu-Addo G, Phillips RO. Pulmonary aspergilloma: an evasive disease. Int $\mathrm{J}$ Mycobacteriol. 2016;5(2):235-9.

21. Jeong YJ, Lee KS. Pulmonary tuberculosis: up-to-date imaging and management. Am J Roentgenol. 2008;191(3):834-44.

22. Boruah DK, Sanyal S, Sharma BK, Prakash A, Dhingani DD, Bora $\mathrm{K}$. Role of cross sectional imaging in isolated chest wall tuberculosis. J Clin Diagn Res. 2017;11(1):TC01-6.

23. Martinez S, McAdams HP, Batchu CS. The many faces of pulmonary nontuberculous mycobacterial infection. AJR Am J Roentgenol. 2007;189(1):177-86.

24. Marchiori E, Müller NL, Soares Souza A Jr, Escuissato DL, Gasparetto EL, Franquet T. Pulmonary disease in patients with AIDS: high-resolution CT and pathologic findings. Am J Roentgenol. 2005;184(3):757-64.

25. Benson CA, Ellner JJ. Mycobacterium avium complex infection and AIDS: advances in theory and practice. Clin Infect Dis. 1993;17(1):7-20.

26. Levin DL. Radiology of pulmonary Mycobacterium aviumintracellulare complex. Clin Chest Med. 2002;23(3):603-12.

27. Phillips P, Bonner S, Gataric N, Bai T, Wilcox P, Hogg R, et al. Nontuberculous mycobacterial immune reconstitution syndrome in HIV-infected patients: spectrum of disease and long-term followup. Clin Infect Dis. 2005;41(10):1483-97.

28. Bennett C, Vardiman J, Golomb H. Disseminated atypical mycobacterial infection in patients with hairy cell leukemia. Am J Med. 1986;80(5):891-6.

29. Marras TK, Wallace RJ Jr, Koth LL, Stulbarg MS, Cowl CT, Daley CL. Hypersensitivity pneumonitis reaction to Mycobacterium avium in household water. Chest. 2005;127(2):664-71.

30. Chong S, Lee KS, Yi CA, Chung MJ, Kim TS, Han J. Pulmonary fungal infection: imaging findings in immunocompetent and immunocompromised patients. Eur J Radiol. 2006;59(3):371-83.
31. Fox DL, Müller NL. Pulmonary cryptococcosis in immunocompetent patients: CT findings in 12 patients. Am J Roentgenol. 2005; 185(3):622-6.

32. Zinck SE, Leung AN, Frost M, Berry GJ, Müller NL. Pulmonary cryptococcosis: CT and pathologic findings. J Comput Assist Tomogr. 2002;26(3):330-4.

33. Capone D, Marchiori E, Wanke B, Dantas KE, Cavalcanti MA, Deus Filho A, Escuissato DL, Warszawiak D. Acute pulmonary coccidioidomycosis: CT findings from 15 patients. Br J Radiol. 2008;81(969):721-4.

34. Kim KI, Leung AN, Flint JD, Müller NL. Chronic pulmonary coccidioidomycosis: computed tomographic and pathologic findings in 18 patients. Can Assoc Radiol J. 1998;49(6):401-7.

35. Kousha M, Tadi R, Soubani AO. Pulmonary aspergillosis: a clinical review. Eur Respir Rev. 2011;20(121):156-74.

36. Denning DW, Cadranel J, Beigelman-Aubry C, Ader F, Chakrabarti A, Blot S, European Society for Clinical Microbiology and Infectious Diseases and European Respiratory Society, et al. Chronic pulmonary aspergillosis: rationale and clinical guidelines for diagnosis and management. Eur Respir J. 2016;47(1):45-68.

37. Desai SR, Hedayati V, Patel K, Hansell DM. Chronic aspergillosis of the lungs: unravelling the terminology and radiology. Eur Radiol. 2015;25(10):3100-7.

38. Feurestein IM, Archer A, Pluda JM, Francis PS, Falloon J, Masur $\mathrm{H}$, et al. Thin-walled cavities, cysts, and pneumothorax in Pneumocystis carinii pneumonia: further observations with histopathologic correlation. Radiology. 1990;174(3 Pt 1):697-702.

39. Miller WT Jr, Mickus TJ, Barbosa E Jr, Mullin C, Van Deerlin VM, Shiley KT. CT of viral lower respiratory tract infections in adults: comparison among viral organisms and between viral and bacterial infections. Am J Roentgenol. 2011;197(5):1088-95.

40. Komiya K, Ishii H, Kushima H, Sato S, Kimura H, Yasuda T, Okabe E, Tokimatsu I, Yamamoto H, Kadota J. Physicians' attitudes toward the definition of "death from age-related physical debility" in deceased elderly with aspiration pneumonia. Geriatr Gerontol Int. 2013;13(3):586-90. 